\title{
Carbon Characterization Laboratory Report
}

David Swank William Windes

D.C. Haggard

David Rohrbaugh

Karen Moore

March 2009
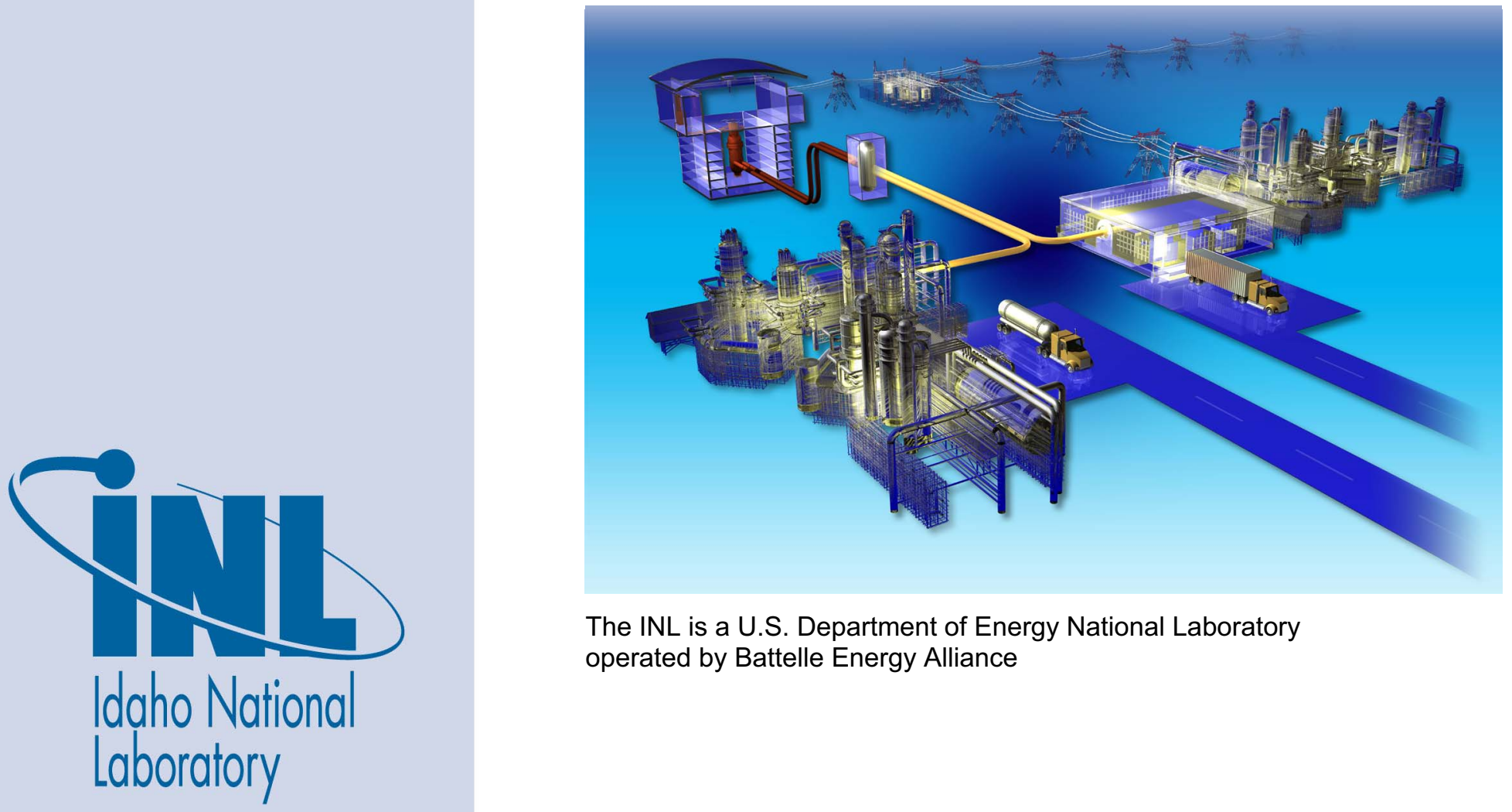

The INL is a U.S. Department of Energy National Laboratory operated by Battelle Energy Alliance 
INL/EXT-09-15515

\title{
Carbon Characterization Laboratory Report
}

\author{
David Swank \\ William Windes \\ D. C. Haggard \\ David Rohrbaugh \\ Karen Moore
}

March 2009

\section{Idaho National Laboratory \\ Next Generation Nuclear Plant Project \\ Idaho Falls, Idaho 83415}

http://www.inl.gov

Prepared for the

U.S. Department of Energy

Office of Nuclear Energy

Under DOE Idaho Operations Office

Contract DE-AC07-05ID14517 


\section{DISCLAIMER}

This information was prepared as an account of work sponsored by an agency of the U.S. Government. Neither the U.S. Government nor any agency thereof, nor any of their employees, makes any warranty, expressed or implied, or assumes any legal liability or responsibility for the accuracy, completeness, or usefulness, of any information, apparatus, product, or process disclosed, or represents that its use would not infringe privately owned rights. References herein to any specific commercial product, process, or service by trade name, trade mark, manufacturer, or otherwise, does not necessarily constitute or imply its endorsement, recommendation, or favoring by the U.S. Government or any agency thereof. The views and opinions of authors expressed herein do not necessarily state or reflect those of the U.S. Government or any agency thereof. 
This page is intentionally left blank 
Next Generation Nuclear Plant Project

\title{
Carbon Characterization Laboratory Report
}

\author{
INL/EXT-09-15515 \\ Revision 0
}

March 2009

Approved by:

William Windes

Date

VHTR TDO Graphite R\&D Lead

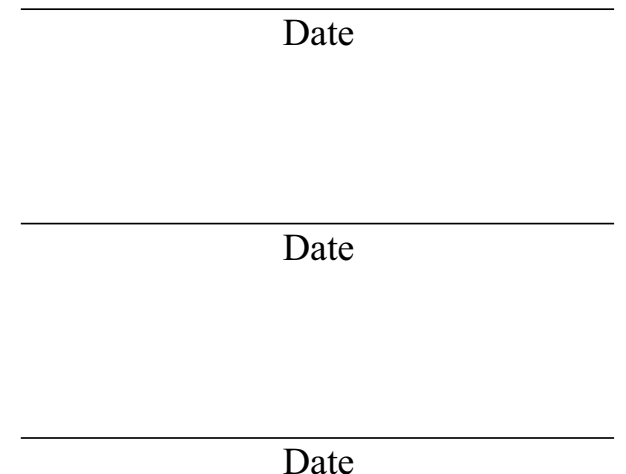

Gary Roberts

VHTR TDO Quality Assurance Lead

Date 
This page is intentionally left blank 


\section{SUMMARY}

The newly completed Idaho National Laboratory (INL) Carbon Characterization Laboratory (CCL) is located in Lab-C20 of the Idaho National Laboratory Research Center. This laboratory was established under the Next Generation Nuclear Plant (NGNP) Project to support graphite research and development activities. The CCL is designed to characterize and test carbonbased materials such as graphite, carbon-carbon composites, and silicon-carbide composite materials. The laboratory is fully prepared to measure material properties for nonirradiated carbon-based materials. Plans to establish the laboratory as a radiological facility within the next year are definitive. The laboratory will be modified to accommodate irradiated materials, after which it can be used to perform material property measurements on both irradiated and nonirradiated carbon-based material.

Instruments, fixtures, and methods are in place for preirradiation measurements of bulk density, thermal diffusivity, coefficient of thermal expansion, elastic modulus (Young's modulus, Shear modulus, Poisson ratio), and electrical resistivity. The measurement protocol consists of functional validation, calibration, and automated data acquisition. Functional validations have been established for each measurement in collaboration with the instrument manufacturer and are performed periodically to verify the acquisition of accurate and consistent data. All validations are performed on traceable standards and documented in retrievable laboratory notebooks associated with each measurement. Calibration standards, methods, and frequencies have also been established for each measurement. Where it is not possible to use the INL Standards and Calibration Laboratory, calibration by user procedures are established based on American Society for Testing and Materials standards and manufacturer's instructions and are performed against international standards. These procedures are documented in laboratory notebooks.

Significant improvements in specimen fixtures and data acquisition have been made specifically for preirradiation material property measurements in support of the Advanced Test Reactor Graphite Creep (AGC) experiment-a major material irradiation experiment within the NGNP Graphite program. These material property measurements are divided into individual measurement stations that consist of the instrumentation necessary to make the measurement, a computer for automated data acquisition, and a bar code reader. Each specimen is bar coded with its unique identity, and prior to each measurement, the specimen's identity is automatically read and input. Automated data acquisition software has been written in LabVIEW for measurements of sonic velocity, fundamental frequency, electrical resistivity, and mass. This software takes the instrumentation output and interfaces it to Excel spreadsheets. This automated specimen identification and data acquisition eliminates data entry errors and significantly improves efficiency. The CCL is fully operational and ready to characterize the AGC-2 specimens before insertion into the irradiation capsule. As experience is gained using the equipment, improvements in measurement accuracy, precision, and method will be evaluated for possible improvements. If these changes are determined to be significant and beneficial, modification of the specific ASTM standard or measurement technique will be suggested. 
This page is intentionally left blank 


\section{CONTENTS}

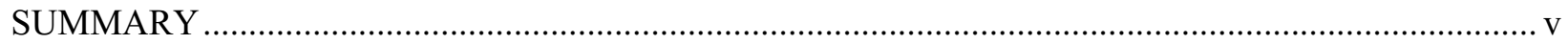

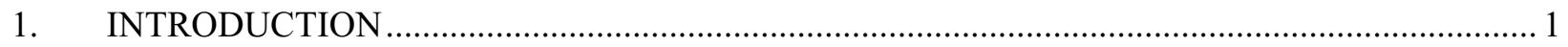

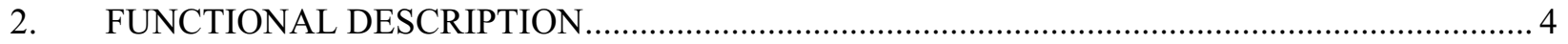

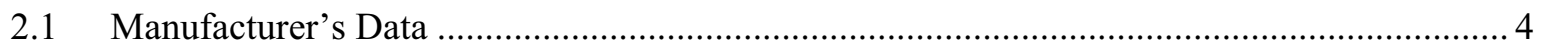

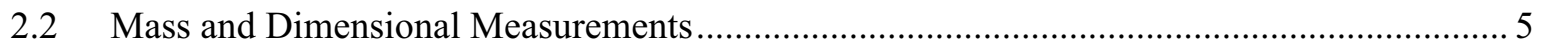

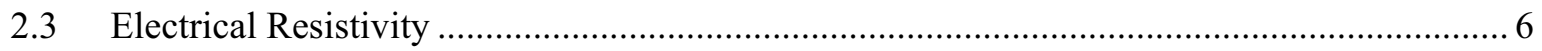

2.4 Approximation of Elastic Modulus from the Measurement of Sonic Velocity .................... 8

2.5 Modulus of Elasticity by Fundamental Frequency Measurement.......................................... 9

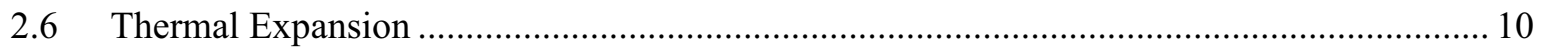

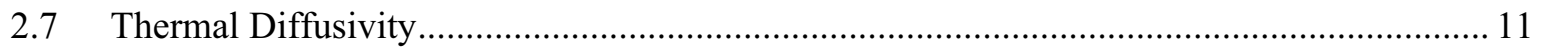

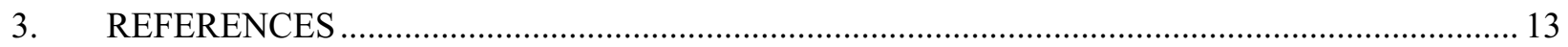

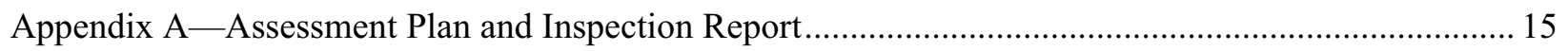

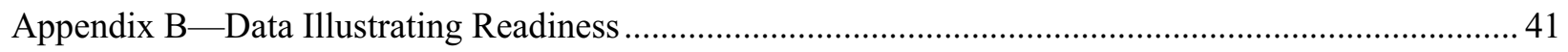

\section{FIGURES}

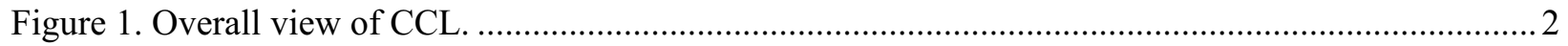

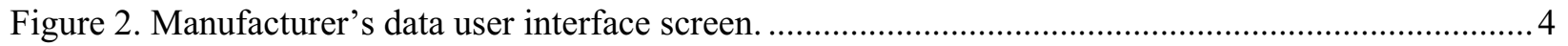

Figure 3. Excel data spreadsheet example of the "manufacturer's data" tab............................................5

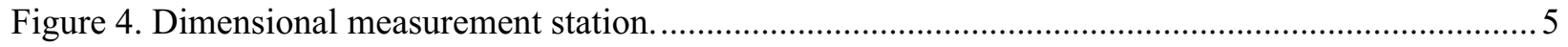

Figure 5. Physical and dimensional measurements program user interface. ............................................. 6

Figure 6. Electrical resistivity measurement station. …........................................................................ 7

Figure 7. Software user interface for electrical resistivity ...................................................................

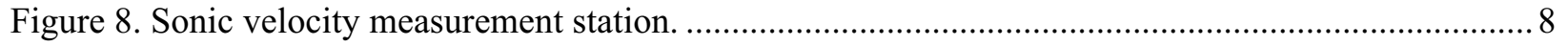

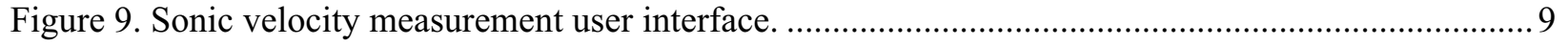

Figure 10. Fundamental frequency measurement station. …............................................................... 9

Figure 11. User interface for fundamental frequency measurements. .................................................. 10

Figure 12. Commercial push rod dilatometer for measurement of CTE ................................................ 11

Figure 13. LFA measurement station for determination of thermal diffusivity...................................... 12

\section{TABLES}

Table 1. CCL measurement and test equipment. 2 
This page is intentionally left blank 


\section{Carbon Characterization Laboratory Report}

\section{INTRODUCTION}

The Next Generation Nuclear Plant (NGNP) will be a helium cooled high temperature gas-cooled reactor (HTGR) with a large graphite core. The graphite, in the form of large blocks, physically contains the fuel and comprises the majority of the core volume. Graphite has been used effectively as a structural and moderator material in both research and commercial HTGRs. While the general characteristics necessary for producing nuclear grade graphite are understood, historical nuclear grades no longer exist. New grades must therefore be fabricated, characterized, and irradiated to demonstrate that current grades of graphite exhibit acceptable irradiated and nonirradiated properties upon which the thermo-mechanical design of the structural graphite in the NGNP is based. Further details on the research and development (R\&D) activities and associated rationale needed to qualify nuclear grade graphite for use within the NGNP are documented. ${ }^{1,2}$

The newly completed Idaho National Laboratory (INL) Carbon Characterization Laboratory (CCL) is located in Lab-C20 of the INL Research Center. This laboratory was established under the NGNP Project to support graphite R\&D activities. The CCL is designed to characterize and test carbon-based materials such as graphite, carbon-carbon composites, and silicon-carbide composite materials. Initial studies will focus on graphite in support of the NGNP project and will eventually test and characterize irradiated graphite samples after the CCL has been modified into a radiological facility. A preliminary design outlining the modifications necessary to achieve radiological status has been completed, and plans are in place to begin this work within 12 months.

Instruments, fixtures, and methods are currently in place for preirradiation material property measurements of bulk density, thermal diffusivity, coefficient of thermal expansion, elastic modulus (Young's modulus, Shear modulus, Poisson ratio), and electrical resistivity. Table 1 lists the instruments, material property measured, and American Society for Testing and Materials (ASTM) standard to which each measurement is performed. The measurement protocol consists of functional validation, calibration, and automated data acquisition. Functional validations have been established for each measurement in collaboration with the instrument manufacturer and are performed periodically to verify that accurate and consistent data is acquired. All validations are performed on traceable standards and documented in retrievable laboratory notebooks associated with each measurement. Calibration standards, methods, and frequencies have also been established for each measurement. Where it is not possible to use the INL Standards and Calibration Laboratory, calibration by user procedures are established that are based on ASTM standards and manufacturer's instructions, and performed against international standards. These procedures are documented in laboratory notebooks. An overall view of the CCL is shown in Figure 1.

Significant improvements in specimen fixtures and data acquisition have been made specifically to support Advanced Test Reactor Graphite Creep (AGC) sample measurements. The measurements listed in Table 1 are divided into individual measurement stations that consist of the instrumentation necessary to make the measurement, a computer for automated data acquisition, and a bar code reader. Each specimen is bar coded with a unique identity that is automatically read and input prior to each measurement. Automated data acquisition software has been written in LabVIEW for measuring sonic velocity, fundamental frequency, electrical resistivity, and mass. This software interfaces the instrumentation output with Excel spreadsheets. This automated specimen identification and data acquisition eliminates all data entry errors and significantly improves efficiency. The CCL is fully operational and ready to characterize the AGC-2 specimens. As experience is gained using the equipment, improvements in accuracy, precision, and efficiency will be made. 
Table 1. CCL measurement and test equipment.

\begin{tabular}{|c|c|c|c|c|}
\hline Measurement & Standard & Instrumentation & Calibration Method & Result \\
\hline $\begin{array}{l}\text { Physical } \\
\text { dimensions }\end{array}$ & ASTM C559-05 & $\begin{array}{l}\text { Mitutoyo Micrometer 121-155 } \\
\text { INL ID: } 725884 \\
\text { Mitutoyo Caliper CD-6" CSX } \\
\text { INL ID: } 725813\end{array}$ & $\begin{array}{l}\text { INL Standards and } \\
\text { Calibration Laboratory }\end{array}$ & $\begin{array}{l}\text { Sample } \\
\text { dimensions }\end{array}$ \\
\hline Mass & ASTM C559-05 & $\begin{array}{l}\text { Sartorius Scale ME235P } \\
\text { INL ID: } 412642\end{array}$ & $\begin{array}{l}\text { INL Standards and } \\
\text { Calibration Laboratory }\end{array}$ & Bulk density \\
\hline $\begin{array}{l}\text { Fundamental } \\
\text { Frequency }\end{array}$ & $\begin{array}{l}\text { ASTM C } 747-05 \\
\text { ASTM C1259-08 }\end{array}$ & $\begin{array}{l}\text { J. W. Lemmens Grindosonic } \\
\text { INL ID: } 412850\end{array}$ & $\begin{array}{l}\text { No calibration required } \\
\text { per instrument } \\
\text { manufacture. }\end{array}$ & Elastic modulus \\
\hline Sonic velocity & ASTM C769-05 & $\begin{array}{l}\text { Olympus NDT Sq Wave } \\
\text { Pulser/Receiver 5077PR } \\
\text { Serial No: 080172402 } \\
\text { National Instruments Digitizer } \\
\text { USB 5133 } \\
\text { Serial No: P10239379 }\end{array}$ & $\begin{array}{l}\text { INL Standards and } \\
\text { Calibration Laboratory }\end{array}$ & $\begin{array}{l}\text { Young's } \\
\text { modulus, Shear } \\
\text { modulus, } \\
\text { Poisson ratio }\end{array}$ \\
\hline $\begin{array}{l}4 \text { point } \\
\text { electrical } \\
\text { resistivity }\end{array}$ & ASTM C611-05 & $\begin{array}{l}\text { Kiethly } 6220 \text { Precision Current } \\
\text { Source } \\
\text { INL ID: } 725865 \\
\text { Kiethly } 2182 \mathrm{~A} \text { Nano Voltmeter } \\
\text { INL ID: } 725866\end{array}$ & $\begin{array}{l}\text { INL Standards and } \\
\text { Calibration Laboratory }\end{array}$ & $\begin{array}{l}\text { Electrical } \\
\text { resistivity }\end{array}$ \\
\hline $\begin{array}{l}\text { Laser flash } \\
\text { diffusivity }\end{array}$ & ASTM E1461-01 & $\begin{array}{l}\text { Netzsch LFA } 457 \text { 2ea. } \\
\text { INL ID: } 412855 \\
\text { INL ID: } 412864\end{array}$ & $\begin{array}{l}\text { Calibration by user per } \\
\text { manufactures } \\
\text { instructions }\end{array}$ & $\begin{array}{l}\text { Thermal } \\
\text { diffusivity }\end{array}$ \\
\hline $\begin{array}{l}\text { Push rod } \\
\text { dilatometry }\end{array}$ & ASTM E228-06 & $\begin{array}{l}\text { Netzsch KIL } 402 \text { C 2ea. } \\
\text { INL ID: } 412860 \\
\text { INL ID: } 412861\end{array}$ & $\begin{array}{l}\text { Calibration by user per } \\
\text { manufactures } \\
\text { instructions }\end{array}$ & $\begin{array}{l}\text { Coefficient of } \\
\text { thermal } \\
\text { expansion }\end{array}$ \\
\hline
\end{tabular}

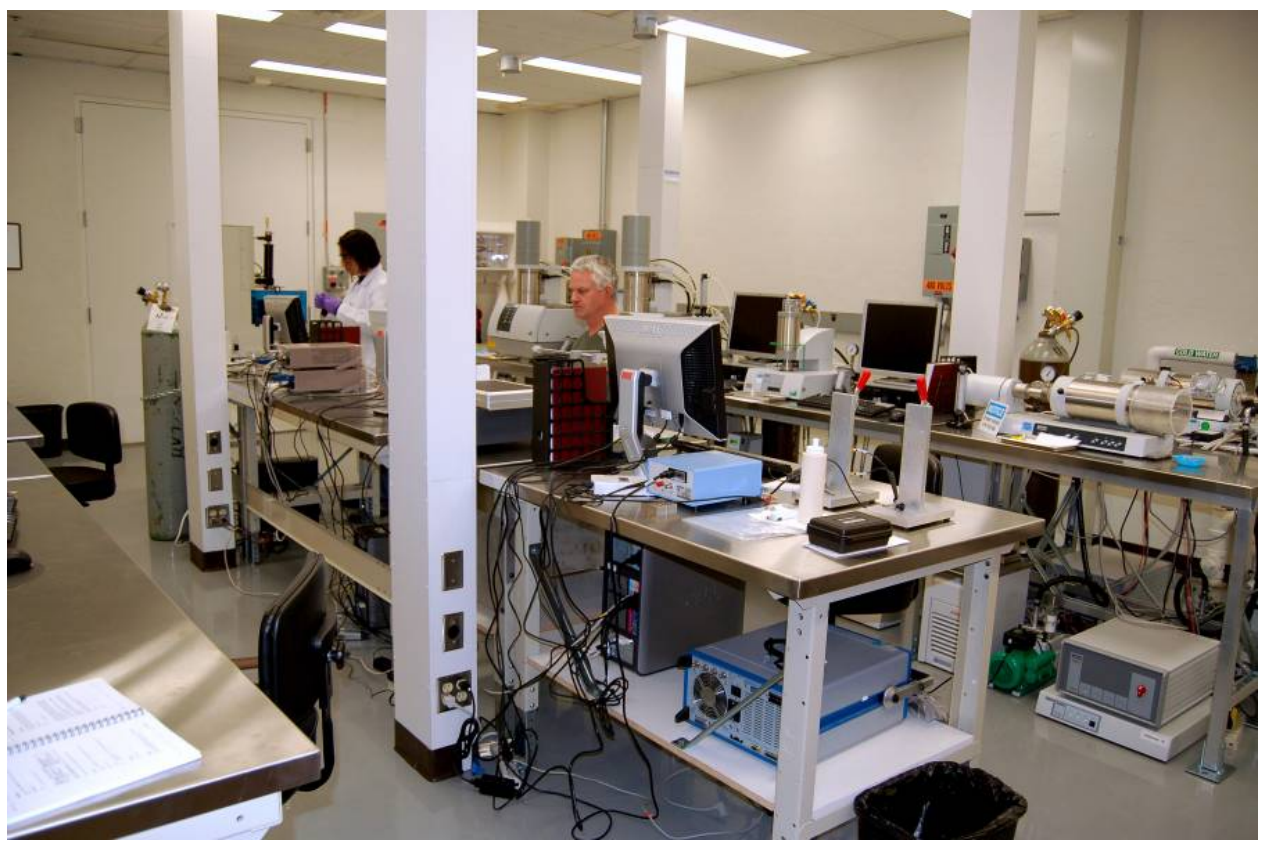

Figure 1. Overall view of CCL. 
This report summarizes the thermal and mechanical measurement techniques that will be used to characterize the different graphite types being tested in AGC experiments. Appendix A contains a detailed Quality Assessment of the CCL's readiness to perform Quality Level 2 measurements. As a final determination of the readiness of the laboratory, 10 representative graphite samples were measured and analyzed by the equipment within the CCL. The data obtained from these tests are summarized in a series of data tables in Appendix B. 


\section{FUNCTIONAL DESCRIPTION}

Six different measurement stations are set up in the CCL to perform preirradiation characterization of AGC graphite: bulk density, thermal diffusivity, coefficient of thermal expansion, Young's modulus, Shear modulus, Poisson ratio, and electrical resistivity. Each station is equipped with measurement fixtures, instrumentation, a data acquisition computer, and a bar code reader. All instruments are networked to a server computer where the measurement data is stored, with the exception of data from thermal diffusivity and coefficient of thermal expansion measurements, which are collected by "off the shelf" instruments with manufacturer's software for automated data collection. All other measurements have been assembled by INL researchers with guidance from Oak Ridge National Laboratory and ASTM standards. Custom LabVIEW software was written to facilitate automated data acquisition. This software is comprised of five main programs: Manufacturers Data, Physical and Dimensional Measurements, Electrical Resistivity Measurements, Sonic Resonance (Fundamental Frequency) Measurements, and Sonic Velocity Measurements. These five programs acquire data from instrumentation or user input and record the results in an Excel spreadsheet that is located on the server computer. Below is a brief description of each of the programs and measurement techniques.

\subsection{Manufacturer's Data}

Before any measurements are made, specimen numbers and basic information about each type of graphite are entered using the manufacturer's data program. Its user interface is shown below in Figure 2. Once basic information about the graphite type has been entered, it is automatically saved to an Excel spreadsheet file and the individual specimen numbers are entered using a bar code reader as shown in Figure 3.

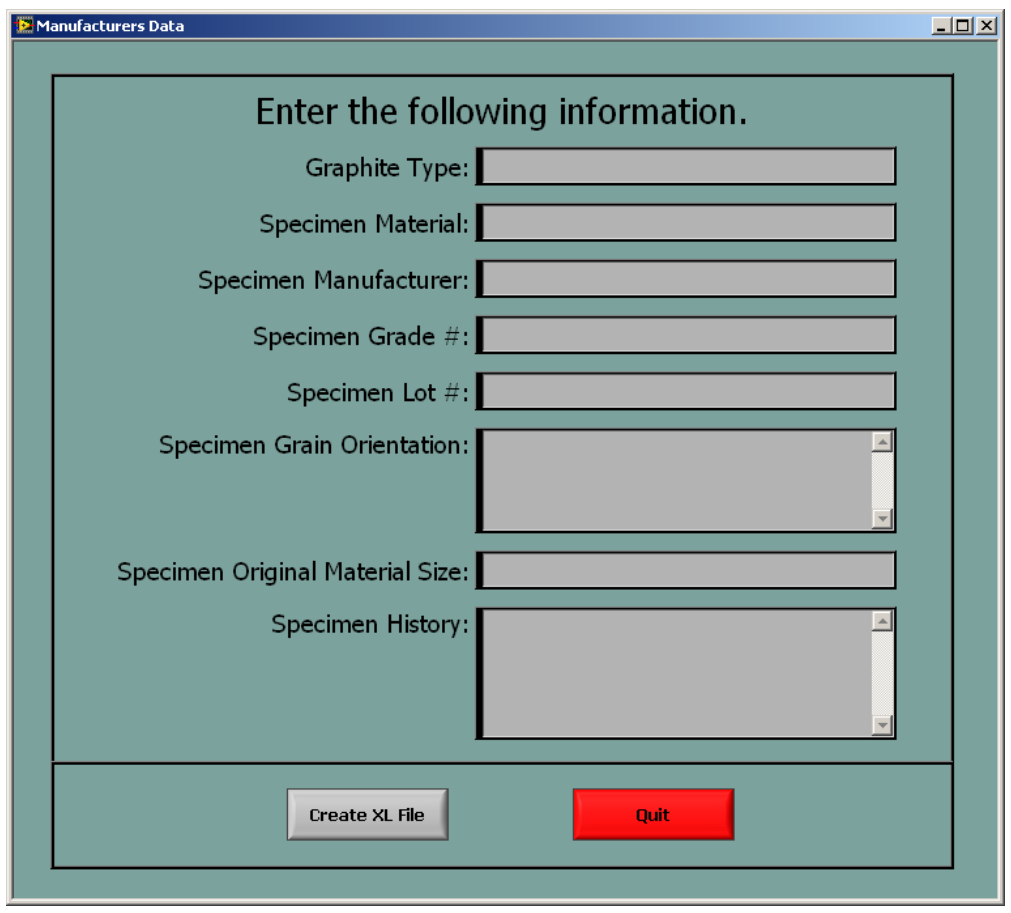

Figure 2. Manufacturer's data user interface screen. 


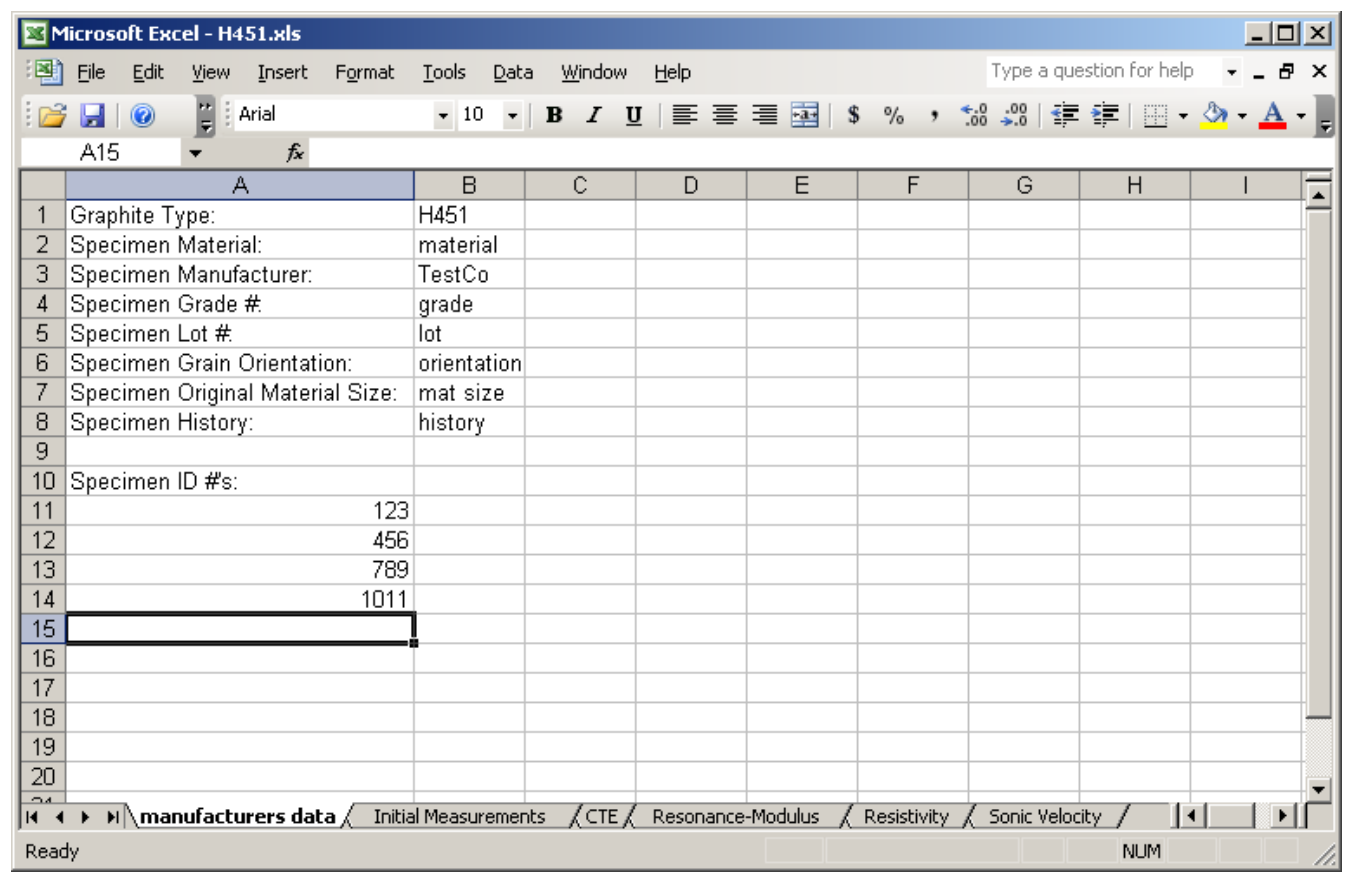

Figure 3. Excel data spreadsheet example of the "manufacturer's data" tab.

\subsection{Mass and Dimensional Measurements}

Dimensional change is one of the key issues affecting the performance of graphite in a neutron environment. Determining volumetric and linear dimensions as functions of temperature and radiological dose will be necessary to understand critical performance measures such as dimensional change turnaround, irradiation creep, and internal stresses imposed upon graphite components. Dimensional and mass measurements are performed to ASTM Standard C559-05, which describes in detail the procedure for making dimensional measurements and calculating bulk density. Dimensional measurements of the specimen radius and length are made with INL calibrated micrometers and calipers. The mass is measured using an INL calibrated electronic balance. Figure 4 shows the dimensional measurement station.

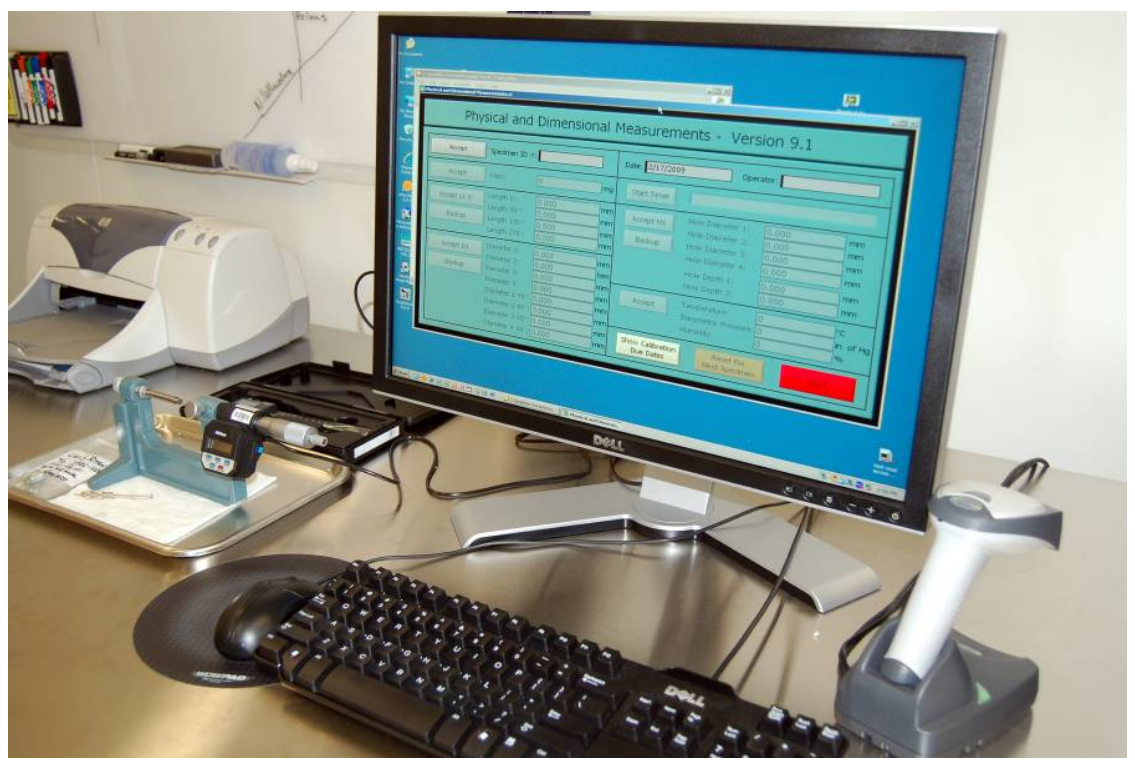

Figure 4. Dimensional measurement station. 
The physical and dimensional measurements program user interface is shown in Figure 5. Measurement values are transferred directly from the measurement tools into the LabVIEW software. Once the physical and dimensional measurements of the specimens are taken, the data is automatically written to the Excel spreadsheet under the "Initial Measurements" tab. This data is used to calculate bulk density and is available for other measurement calculations.

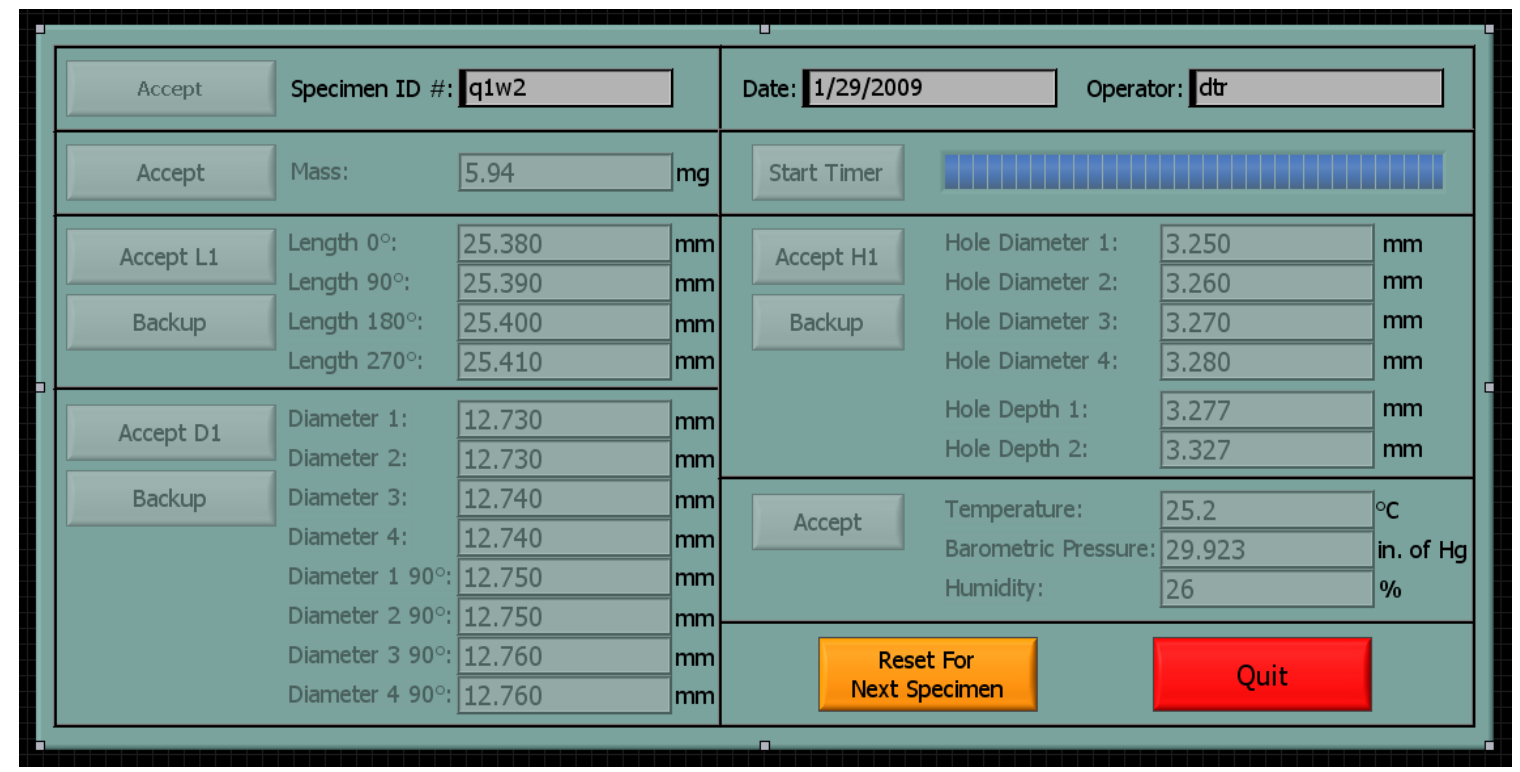

Figure 5. Physical and dimensional measurements program user interface.

\subsection{Electrical Resistivity}

Electrical resistivity is used as a rapid, simple means to determine grain orientation, structure, and crystallinity of the graphite. In conjunction with optical microscopy, it can be used to determine the microstructural texture of the graphite components without much sample preparation work. Resistivity is measured following ASTM C 611-05. The measurement technique is commonly referred to as 4-point probe. It consists of passing a known current through the sample and measuring the voltage across the sample at known locations. Based on Ohms law, the resistance is determined and the resistivity is calculated from

$\rho=R \cdot A / L$

where $\mathrm{R}$ is the measured resistance, $\mathrm{A}$ is the cross sectional area, and $\mathrm{L}$ is the length over which the voltage is measured.

Figure 6 shows the test fixture fabricated at the INL that allows the specimen to be rotated for four measurements of voltage around its periphery. The user interface for electrical resistivity is shown in Figure 7.

The data acquisition screen steps the user through the acquisition process of the voltage and resistance measurement. The program communicates with both a Keithley Model 2182 Nanovoltmeter and a Keithley Model 6220 DC Precision Current Source. Using the current source, a known current is applied across the specimen and the measure voltage is acquired by the software. During data collection, the application calculates the average voltage, average resistance, percent change of the resistance, and ultimately the resistivity. When all of the data has been taken and the user has pressed the "Write Data to File" button, the program saves the results of the test in the resistivity tab of the proper spreadsheet. 


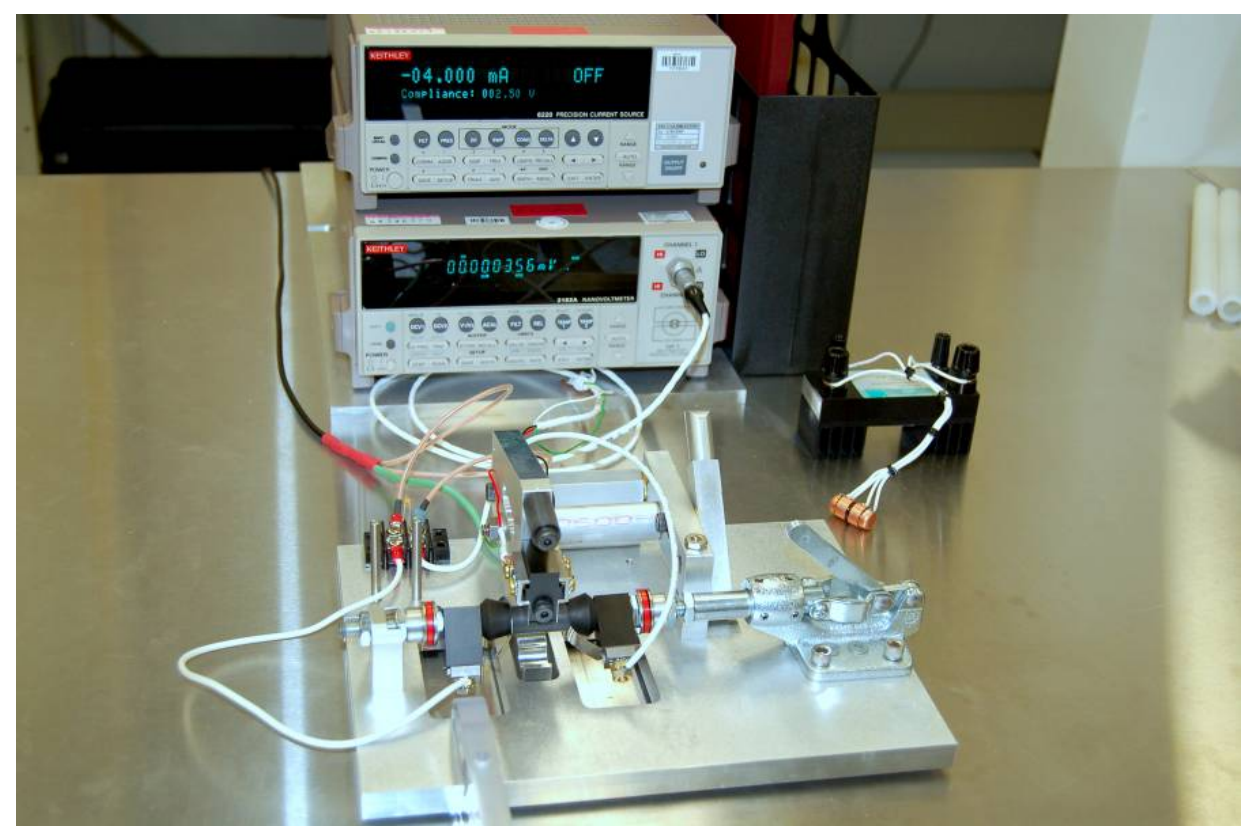

Figure 6. Electrical resistivity measurement station.

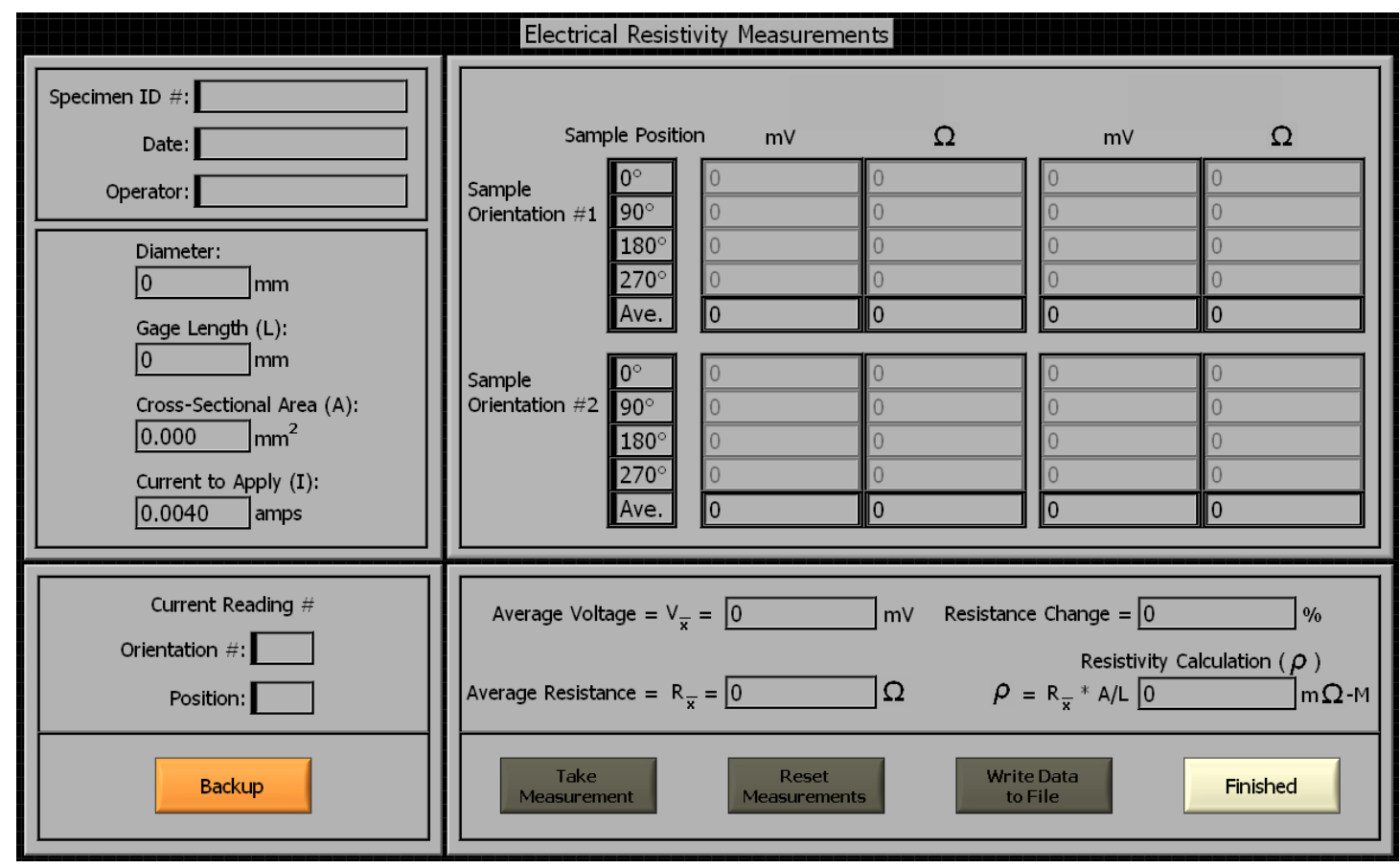

Figure 7. Software user interface for electrical resistivity. 


\subsection{Approximation of Elastic Modulus from the Measurement of Sonic Velocity}

The mechanical properties of graphite are necessary to determine the structural integrity of graphite components. These properties are vital to determining the viability of the structural strength and integrity of the reactor core. The as-received and irradiated values are needed for whole core models, which will be used for the graphite design code. In this measurement the transmitting piezoelectric transducer sends a $2.25 \mathrm{MHz}$ sound wave through the sample. At the opposite end of the sample the acoustic wave is received by another piezoelectric transducer. The sonic velocity of the specimen is the ratio of specimen length to the signal time lapse between transducers. An approximate value for Young's Modulus, E can be obtained from,

$$
E=\rho V^{2}
$$

where $\rho$ is the specimen density and $\mathrm{V}$ is the sonic velocity.

Figure 8 shows the sonic velocity measurement station. In the foreground are the fixtures for clamping the specimen between the transducer and receiver that were specifically designed and fabricated at the INL for this application. They have unique features that improve measurement accuracy, precision, and efficiency. Specimens are easily and rapidly loaded into the fixture using the cam operated clamp. Measurement precision is improved because the spring loaded clamp applies consistent pressure between the transducers and specimen resulting in repeatable couplant thickness.

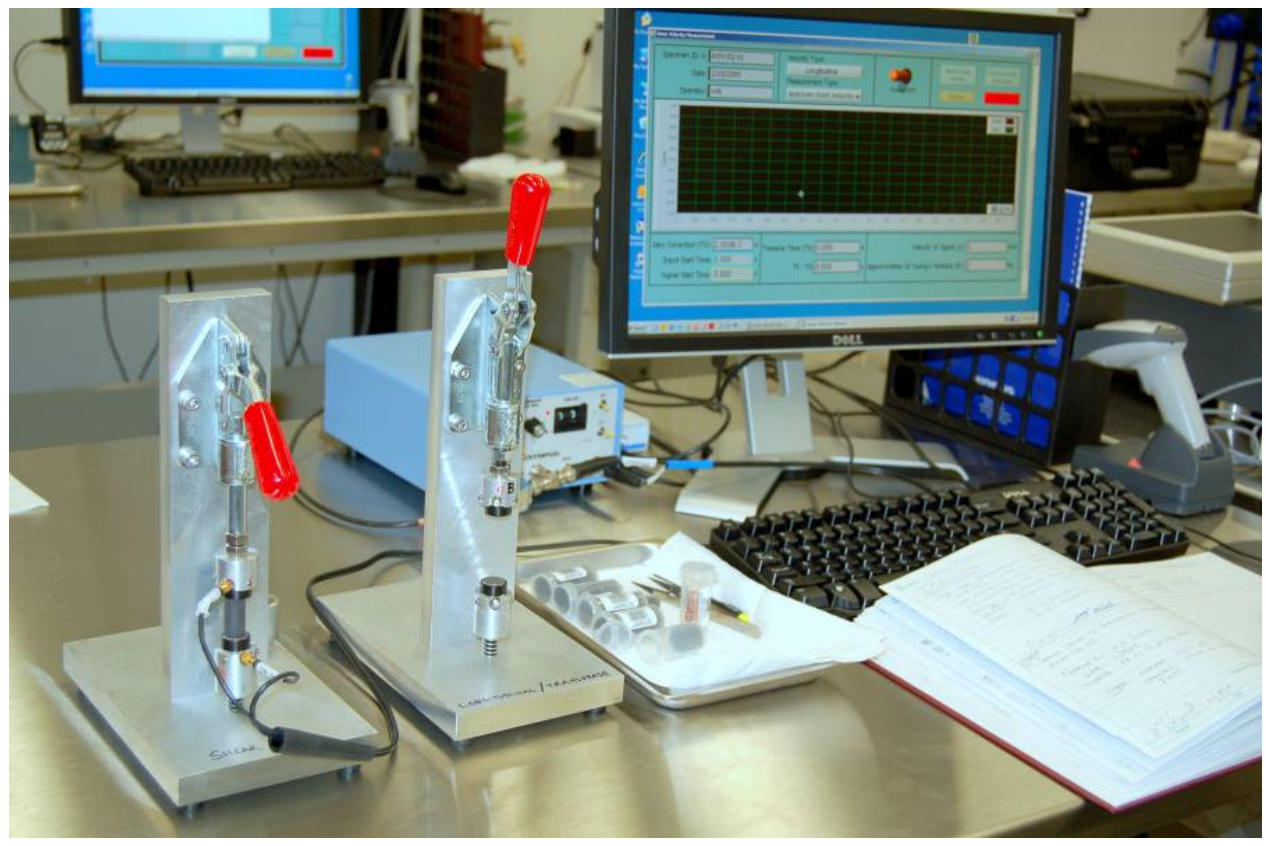

Figure 8 . Sonic velocity measurement station.

Figure 9 shows the LabVIEW software user interface that is displayed after scanning the bar code of the specimen to be tested. This screen is used to acquire sonic velocity measurements of a specimen in both the longitudinal and shear directions. Operating much like an oscilloscope, the cursors automatically mark the time between the transmitted wave and the received wave. The specimen length divided by this transit time is the sonic velocity. 


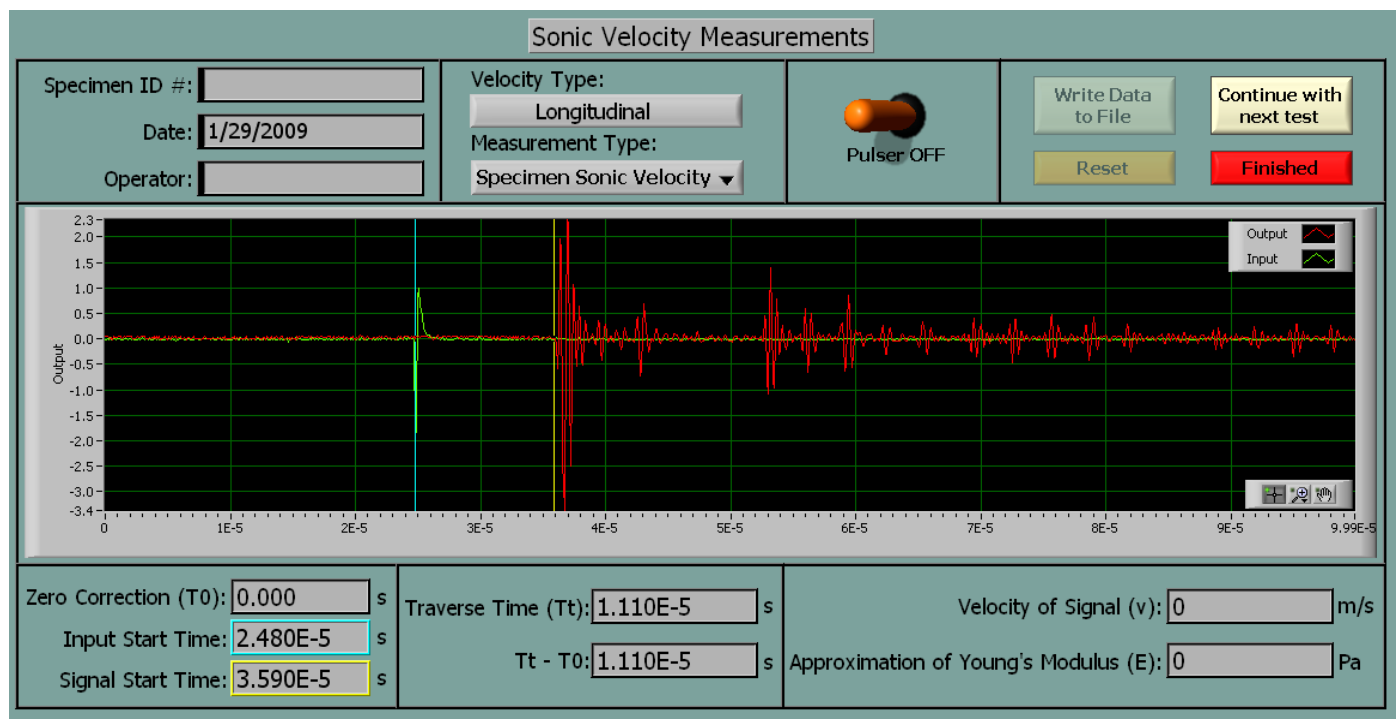

Figure 9. Sonic velocity measurement user interface.

\subsection{Modulus of Elasticity by Fundamental Frequency Measurement}

As stated above, the mechanical properties of graphite are necessary to determine the structural integrity of graphitic components. These properties are vital to determining the viability of the structural strength and integrity of the reactor core. This test method measures the fundamental resonant frequency of test specimens of suitable geometry by exciting them mechanically with a singular elastic strike. Specimen supports, impulse locations, and signal pick-up points are selected to induce and measure specific modes of the transient vibration of the specimen. The transient signals are analyzed, and the fundamental resonant frequency is isolated and measured by the signal analyzer. The measured fundamental resonant frequency, specimen dimensions and mass are used to calculate the dynamic Young's modulus, shear modulus, and Poisson's ratio per ASTM C747-05 in combination with ASTM C1259-08. The fundamental frequency measurement station is shown in Figure 10.

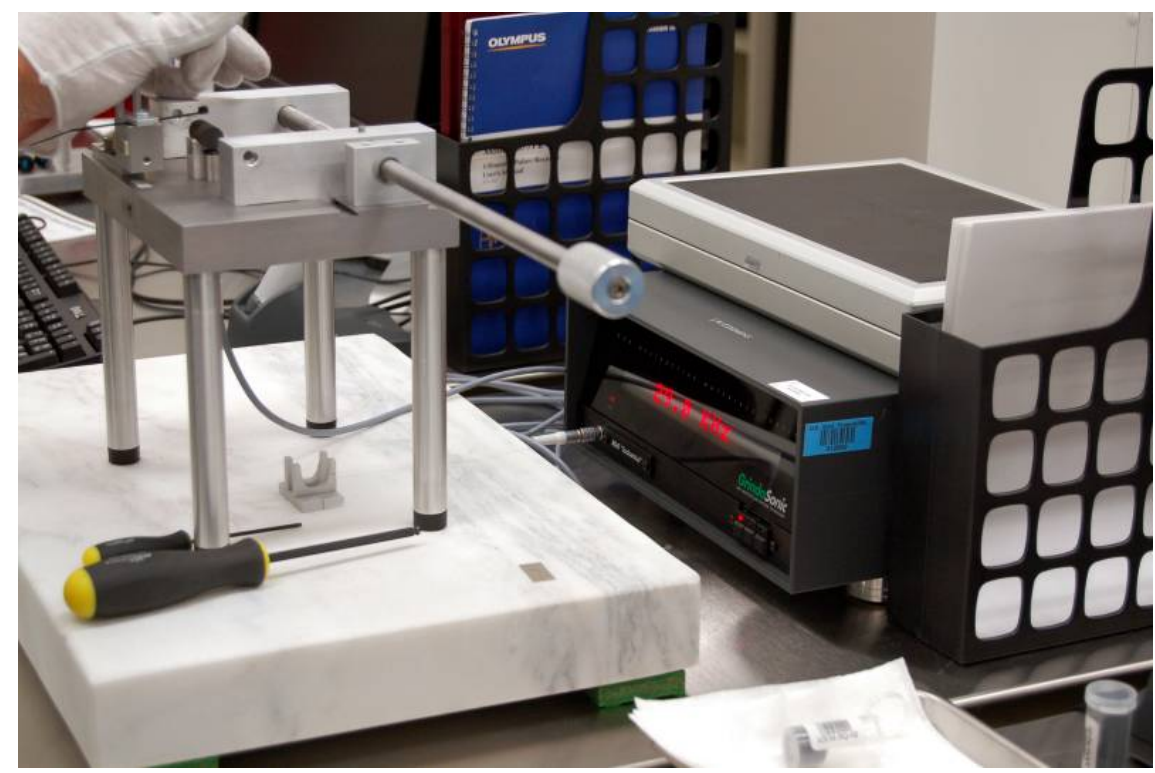

Figure 10. Fundamental frequency measurement station. 
Using the LabVIEW software specifically developed for this project, the user scans the bar code of the specimen. After the specimen's bar code has been scanned and the program confirms that fundamental frequency data doesn't already exist for that specimen, the user interface shown in Figure 11 is displayed.

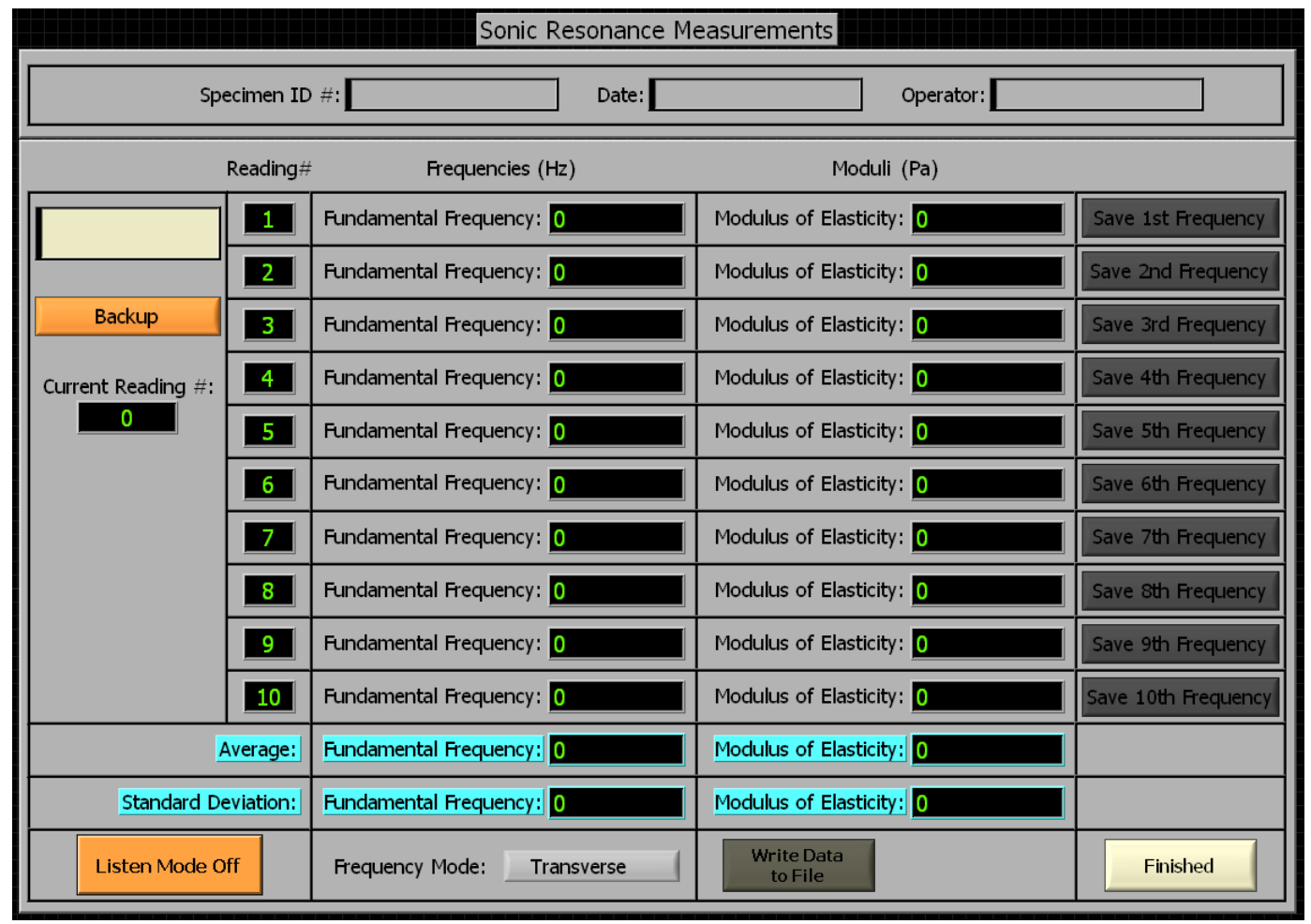

Figure 11. User interface for fundamental frequency measurements.

After placing a specimen in the test fixture, the user excites it by lightly tapping it with a small mechanical impulse. Once the specimen has been excited into vibration, the fundamental frequency is captured by the software and displayed. The modulus of elasticity is calculated and displayed next to the newly acquired frequency. If the results are satisfactory, the user can press the "Save $1{ }^{\text {st }}$ Frequency" button and go on to the next measurement. After all 10 measurements have been made, the results of the test are written to the appropriate Excel spreadsheet.

\subsection{Thermal Expansion}

Understanding the coefficient of thermal expansion (CTE) for graphite components is critical for determining the dimensional changes that occur as a result of temperature cycles. Localized external stresses can be imposed upon mechanically interlocked graphite core components as the individual pieces experience differential thermal expansion. Internal stresses can occur within larger graphite components if there is a temperature gradient causing differential expansion within the piece (one side has a higher temperature than the other). Finally, the thermal expansion is highly dependent upon the graphite microstructure, such as orientation/anisotropy, pore size and distribution, and crystallinity. Irradiation damage can significantly alter graphite microstructure and thus CTE values. Determining the extent of the changes as a function of irradiation dose and temperature will be a key parameter for reliable calculation of stress states within graphite components, volumetric changes, and irradiation creep rates.

This test method uses a push-rod type dilatometer to determine the change in length of a graphite specimen relative to that of the holder as a function of temperature. The temperature is varied over the 
desired range at a slow constant heating or cooling rate. The linear thermal expansion and mean coefficient of thermal expansion, $\alpha$, are calculated from the recorded data using

$\alpha=\frac{1}{L_{0}} \frac{\Delta L}{\Delta T}$

where $\mathrm{L}_{0}$ is the specimen initial length, $\Delta \mathrm{L}$ is the change in length, and $\Delta \mathrm{T}$ is the temperature difference between a specified reference temperature and the temperature at which the change in length was measured. A commercially available push rod dilatometer is used (see Figure 12). It is complete with vendor developed software for instrument control and data acquisition.

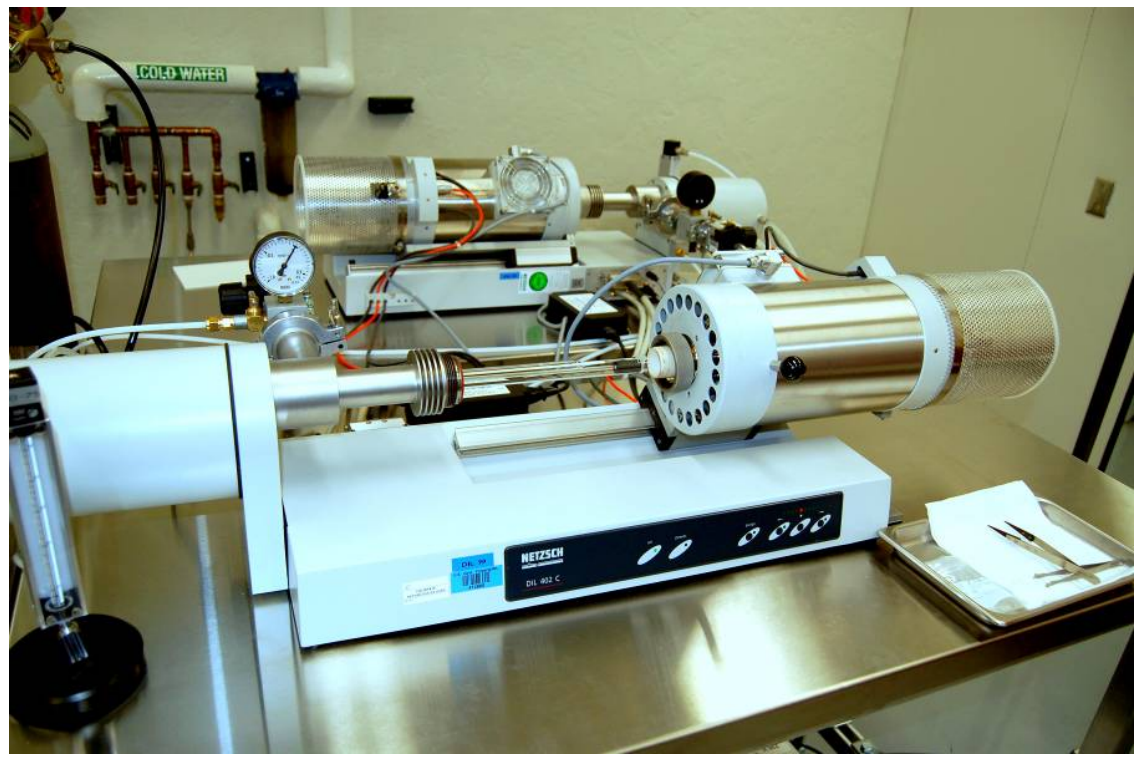

Figure 12. Commercial push rod dilatometer for measurement of CTE.

\subsection{Thermal Diffusivity}

The ability to conduct heat through the graphite core is critical to the passive removal of decay heat. Reduction of the thermal conductivity within graphite can have a significant effect on the passive heat removal rate and thus the peak temperature that the core and, subsequently, the fuel particles will experience during off-normal events. Determining changes to the conductivity as a function of irradiation dose and temperature is important for the HTGR safety analysis. Here, thermal diffusivity $(\delta)$ is measured and defined as the ratio of thermal conductivity to volumetric heat capacity by

$$
\delta=\frac{k}{\rho C_{P}}
$$

where $\mathrm{k}$ is the thermal conductivity, $\rho$ is the density, and $C_{P}$ is the specific heat.

The measurement is performed on small thin disk shaped specimens. A pulsed laser is used to subject one surface of the specimen to a high-intensity short duration energy pulse. The energy of this pulse is absorbed on the front surface of the specimen and the resulting rear face temperature rise is recorded. The thermal diffusivity is calculated from the specimen thickness and the time required for the rear face temperature to reach $50 \%$ of its maximum value. A commercially available Laser Flash Apparatus (LFA), complete with vendor developed software for instrument control and data acquisition, is used as shown in Figure 13. 


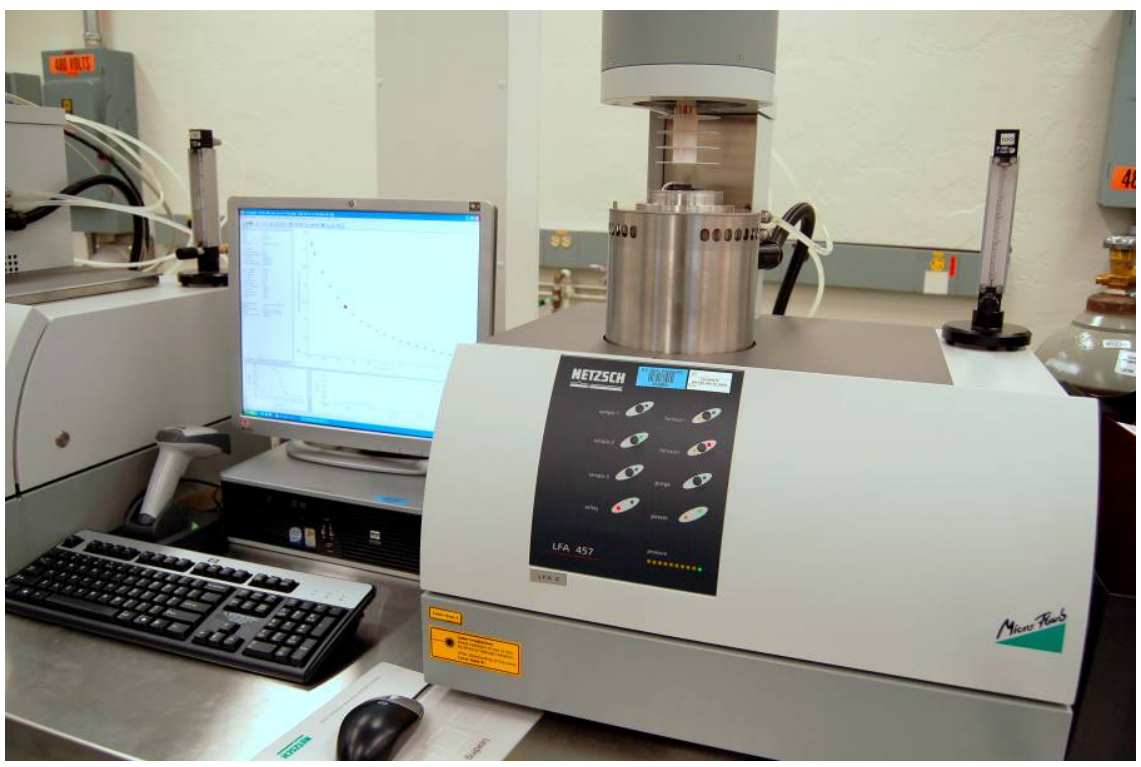

Figure 13. LFA measurement station for determination of thermal diffusivity. 


\section{REFERENCES}

1. W. Windes, T. Burchell, R. Bratton, “AGC-1 Irradiation Experiment Test Plan,” PLN-2497, Rev 0, October 2007.

2. R. L. Bratton and T. D. Burchell, NGNP Graphite Testing and Qualification Specimen Selection Strategy, INL/EXT-05-00269, May 2005. 
This page is intentionally left blank 


\section{Appendix A}

\section{Assessment Plan and Inspection Report}


This page is intentionally left blank 


\section{Appendix A \\ Assessment Plan}

220.21

04/10/2008

Rev. 00

\section{ASSESSMENT PLAN}

Page 1 of 3

Assessment Title: NGNP Work Control Surveillance for Cold Characterization Integrated Assessment System No: IAS081221 of Graphite

Management Assessment $12 /$ estot independent Assessment: $\square$ PURPOSE AND SCOPE OF ASSESSMENT:

The purpose of this inspection is to evaluate the readiness of the Graphite Characterization Laboratory to conduct work.

The scope will include laboratory C-20 and facilities in which graphite characterization support work is being conducted. The scope needs to include these actions: Assess work control implementation, data collection methods, measuring and test equipment controls, material traceability controls, graphite cleanliness controls, training records for graphite characterization work and equipment operating procedures.

APPLICABLE DOCUMENTS (Identified by applicable title, number, and revision):

LWP -13455 Control of Measuring and Test Equipment

PDD -13450 Calibration and Data Integrity

LWP -13120 Identifying And Controlling Items

LWP - 13014 Determining Quality Levels

MCP -2875 Laboratory Notebooks

MCP -1380 Research and Development Test Control

PLN - 1726 Software Control / 414.A86 with NGNP supplements

TEAM MEMBERS (Names, functions, and areas evaluating):

Gary Roberts - Lead Assessor

David R. Jensen - QA staff / Lead Assessor in Training.

ORGANIZATION(S)/PROGRAM(S) TO BE EVALUATED (Identify areas, activities and/or organization numbers and titles):

NGNP-Cold Graphite Specimen Characterization

SCHEDULE (Planning, preassessment meeting, field work duration, exit meeting, and final report issuance):

This assessment has been assigned to start on January 5, 2009 and end on March 1, 2009.

CHECKLIST(S)/LINES OF INQUIRY:

Checklist provided.

Manager(s) of Assessed Organization(s)

This form is used with LWP-13750, "Performing Management Assessments," and LWP-13760, "Performing Independent Assessments."

This form can also be used for any other assessment planning activity. 
220.21

$04 / 10 / 2008$

Rev. 00

\section{ASSESSMENT PLAN}

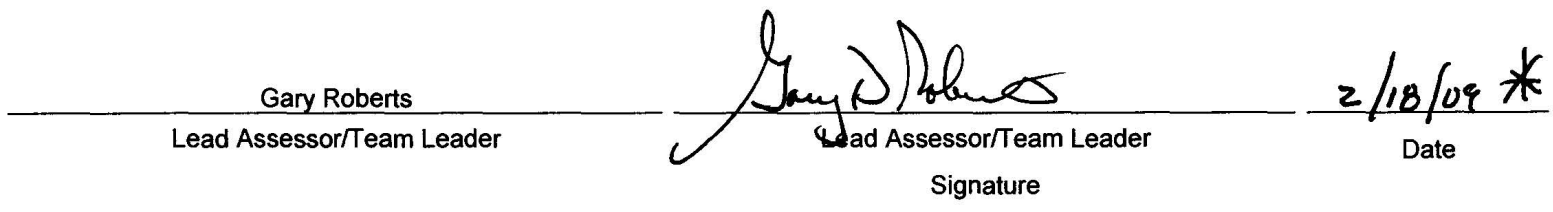

* Asses mant Plon written prior to $1 / 28 / 09$ and all partics were notified of uspection focus $2 / 18 / 09$ timing.

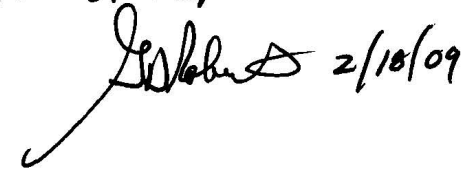

This form is used with LWP-13750, "Performing Management Assessments," and LWP-13760, "Performing Independent Assessments."

This form can also be used for any other assessment planning activity. 


\section{INSTRUCTIONS FOR COMPLETION OF FORM 220.21}

PURPOSE AND SCOPE OF ASSESSMENT: Describe the purpose of the assessment. Purpose provides the reason or objectives for "why" the assessment is being performed. Describe the scope of the assessment. Scope provides the boundaries within which the assessment activity is be performed. Scope should include the "what," "where," and "depth" of the assessment.

APPLICABLE DOCUMENTS: Identified by applicable number, title, and revision of the documents that are the basis for which performance will be evaluated.

be used as a guide throughout the assessment to evaluate performance against requirements and expectations. Checklist(s) and lines of inquiry vary in format, content, and level of detail to focus the assessor on the mission and objectives of the program, system, or process being assessed. They include the performance criteria to the established assessment scope and may include lists of interview questions, major elements of programs, or detailed process work. An attached document is acceptable.

MANAGERS OF ASSESSED ORGANIZATION(S): Identify the manager(s) of the organizations to be assessed. If appropriate, enter the higher level of management when multiple organizations are identified within one directorate.

MANAGER'S SIGNATURE FOR CONCURRENCE: Obtain the manager(s) of the assessed organization's concurrence of the assessment plan.

LEAD ASSESSOR/TEAM LEADER: Enter the name of the lead assessor or team leader.

LEAD ASSESSOR/TEAM LEADER SIGNATURE: Lead assessor's/team leader's signature after concurrence by the assessed organization(s) have been obtained.

COGNIZANT DIRECTOR/MANAGEMENT SYSTEM LEADER: Enter the name of the sponsoring director and management system leader.

COGNIZANT DIRECTOR/MANAGEMENT SYSTEM LEADER SIGNATURE: Sponsoring director's and management system leader's signature.

This form is used with LWP-13750, "Performing Management Assessments," and LWP-13760, "Performing Independent Assessments.

This form can also be used for any other assessment planning activity. 


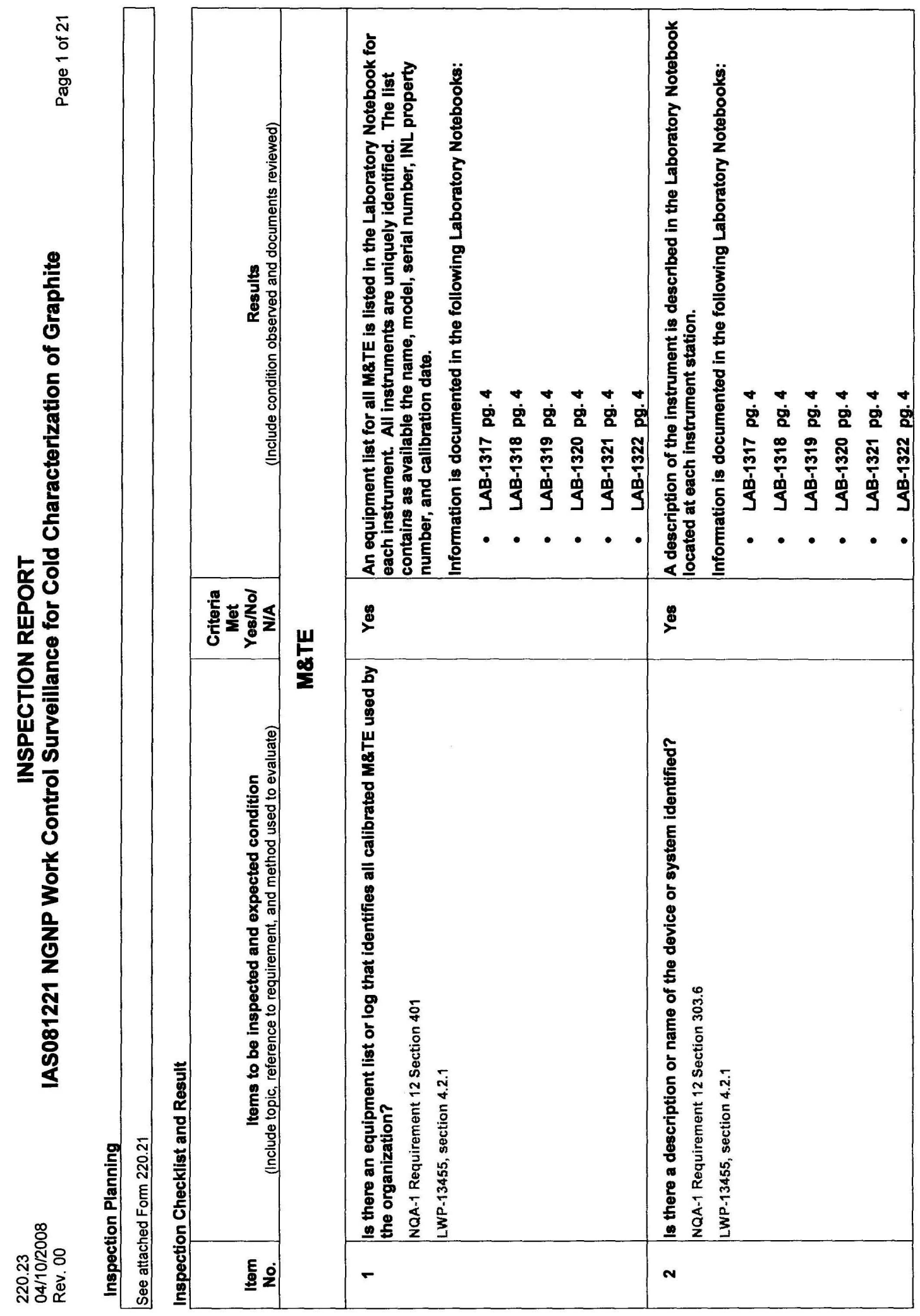

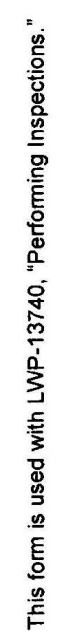




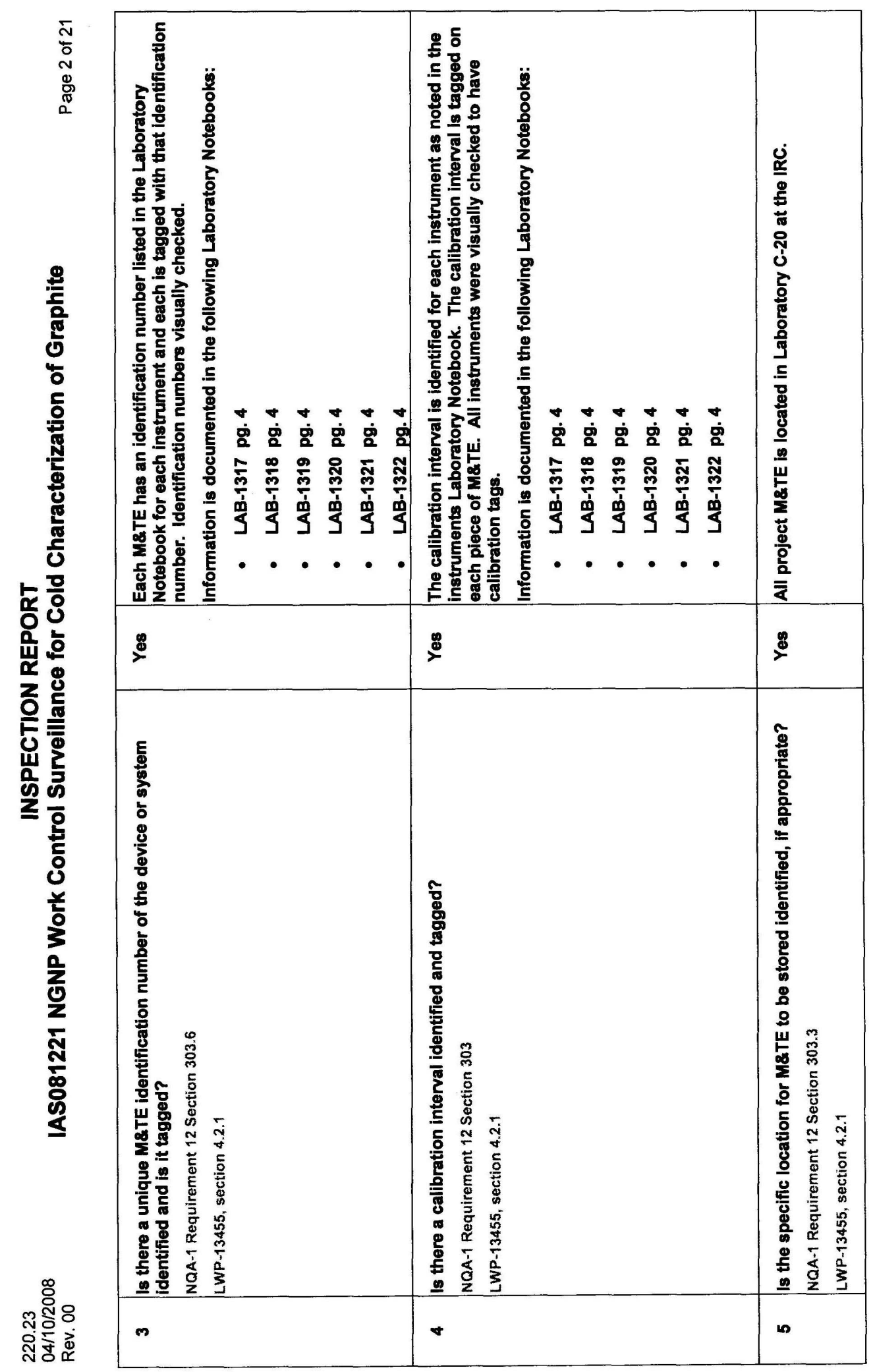

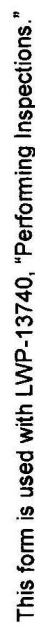




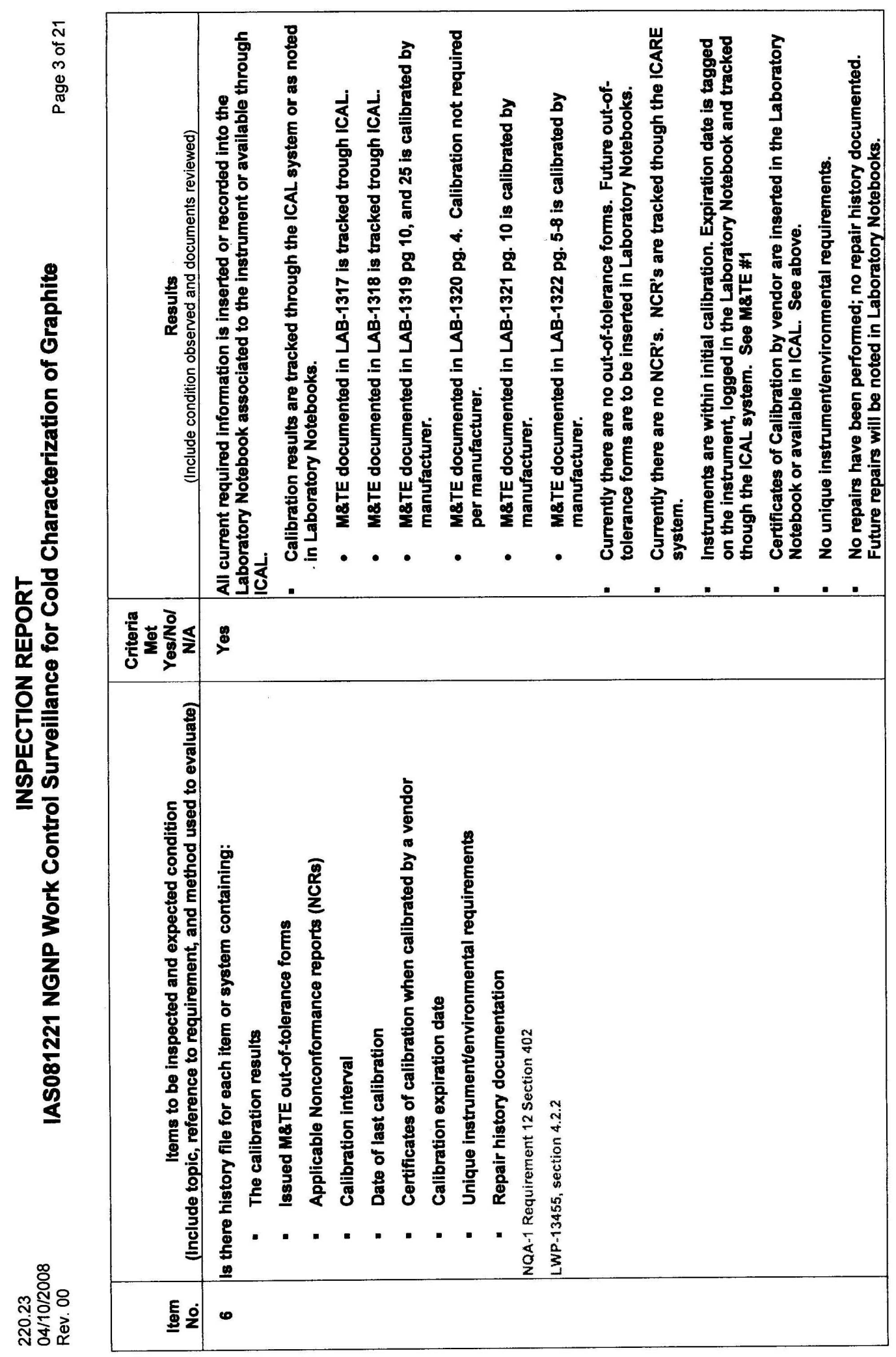




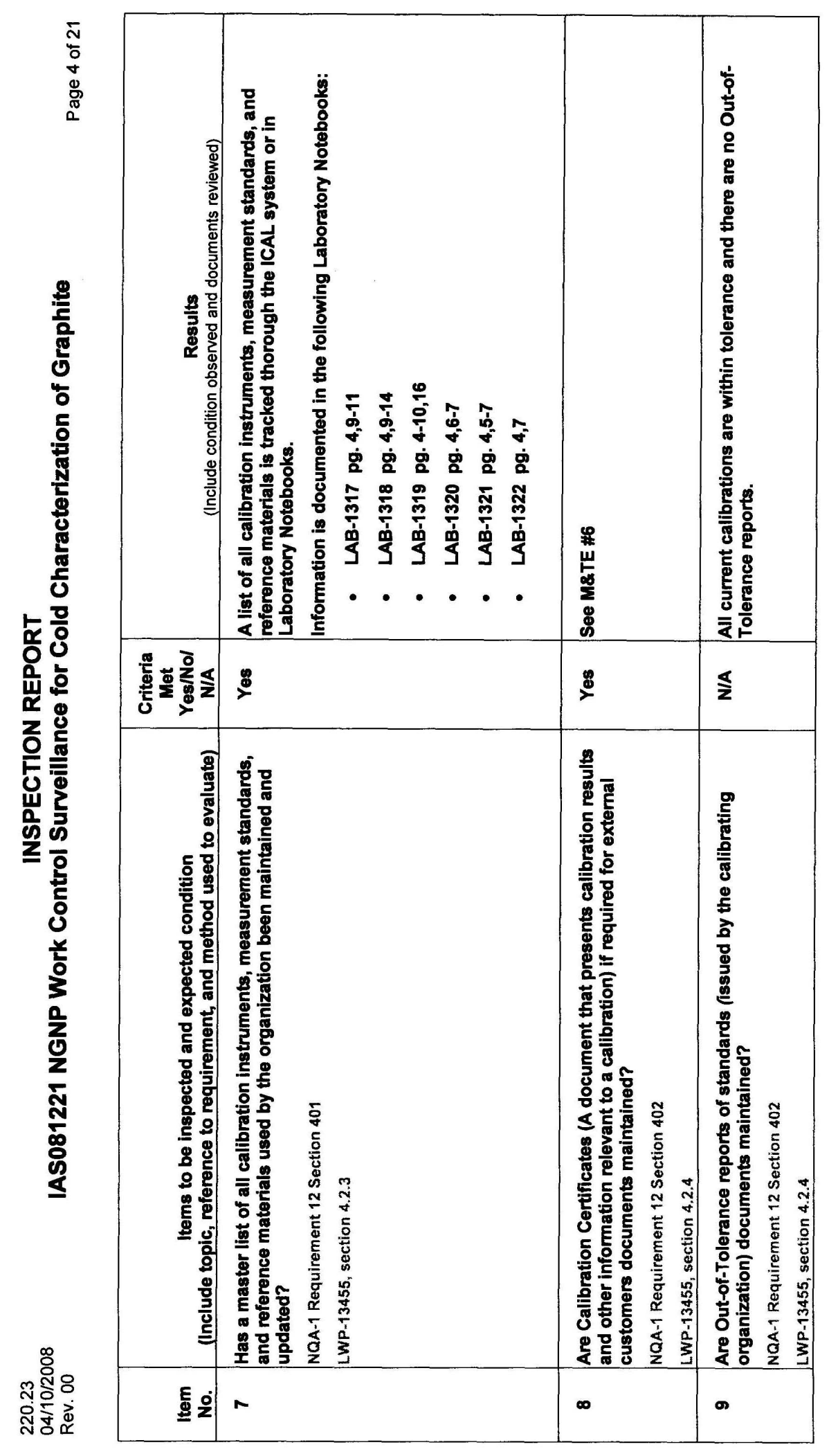

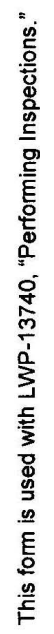




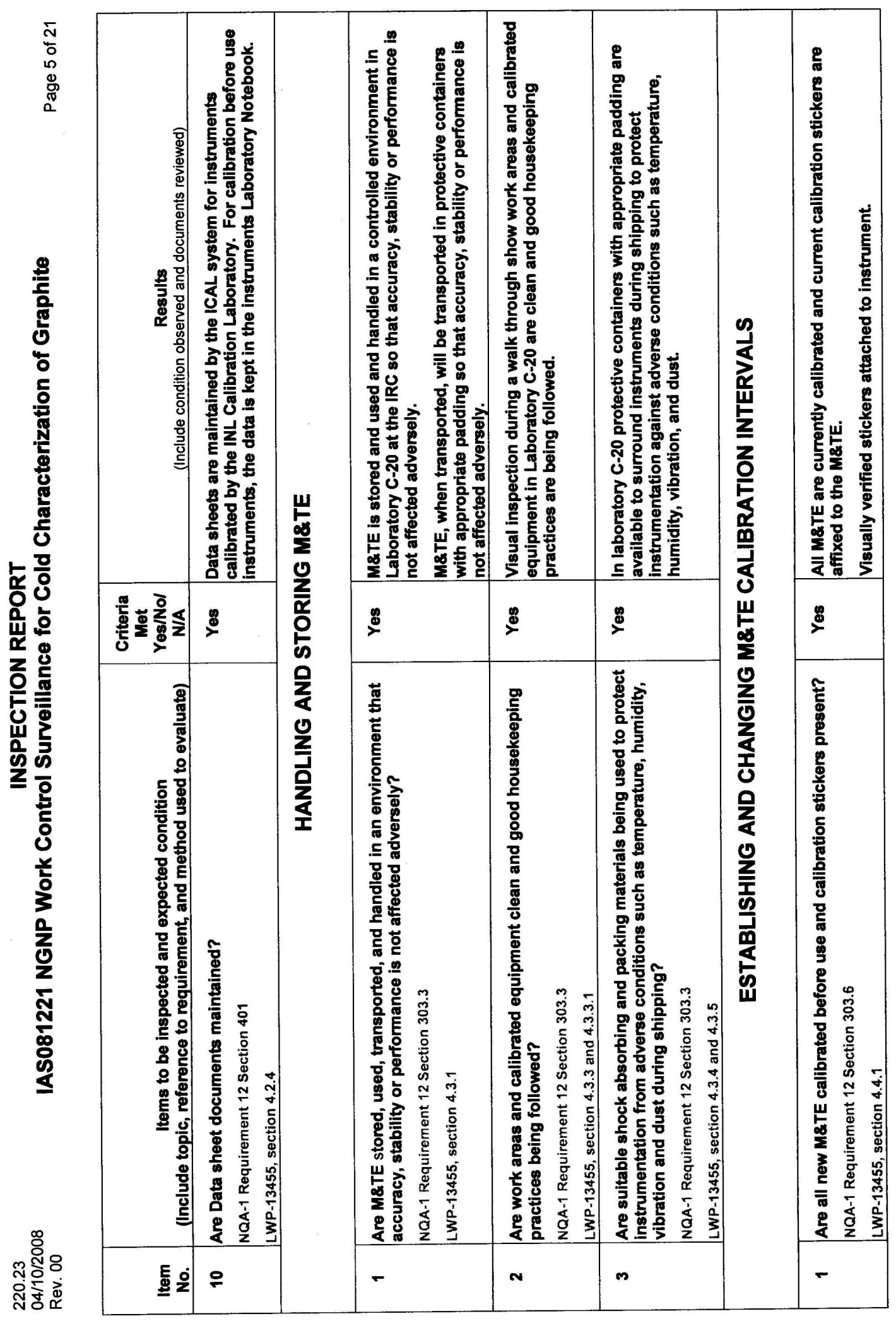

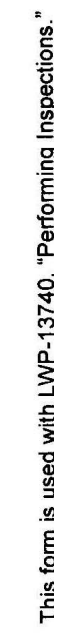




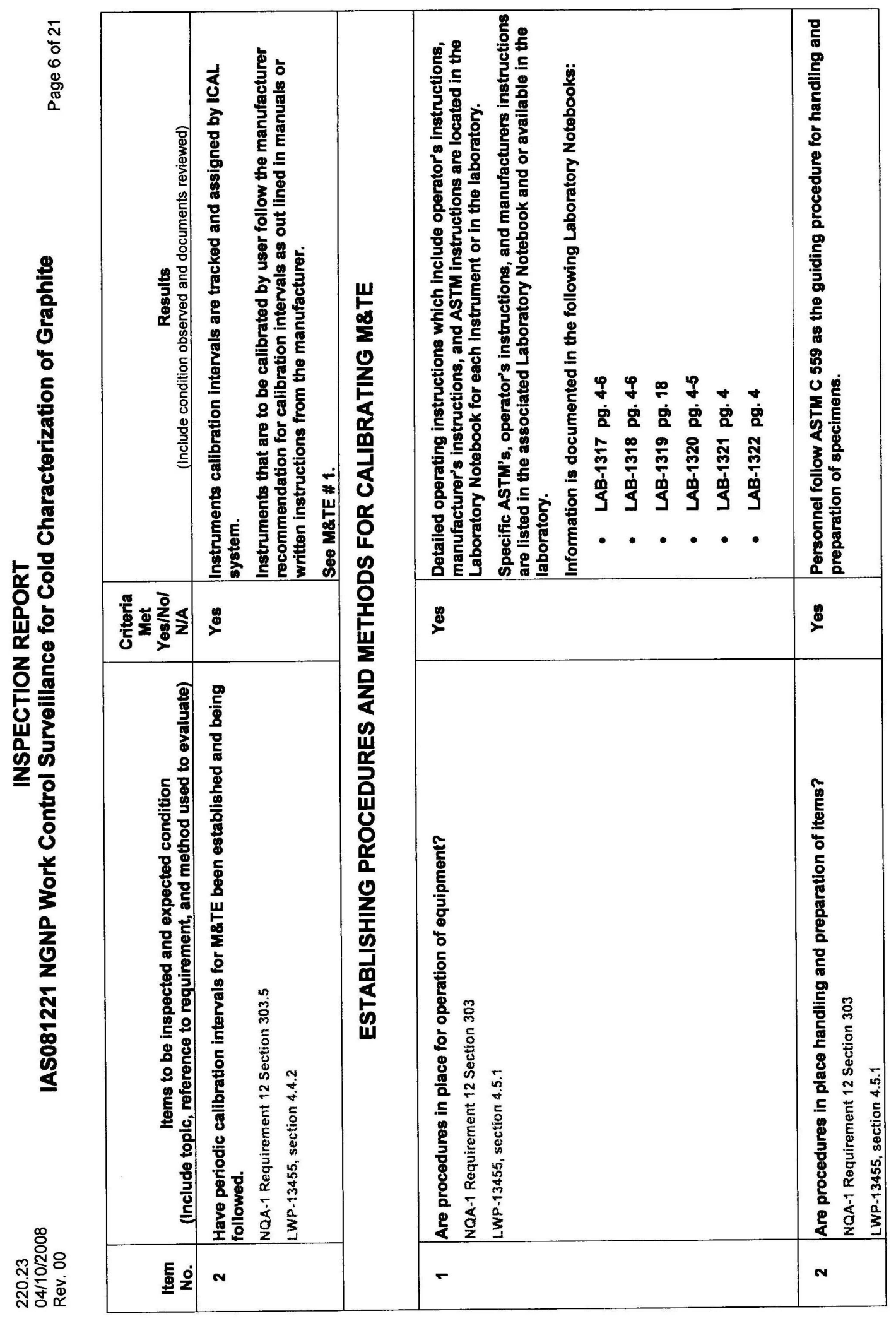

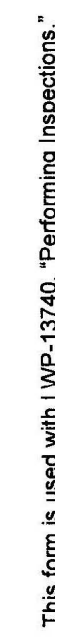




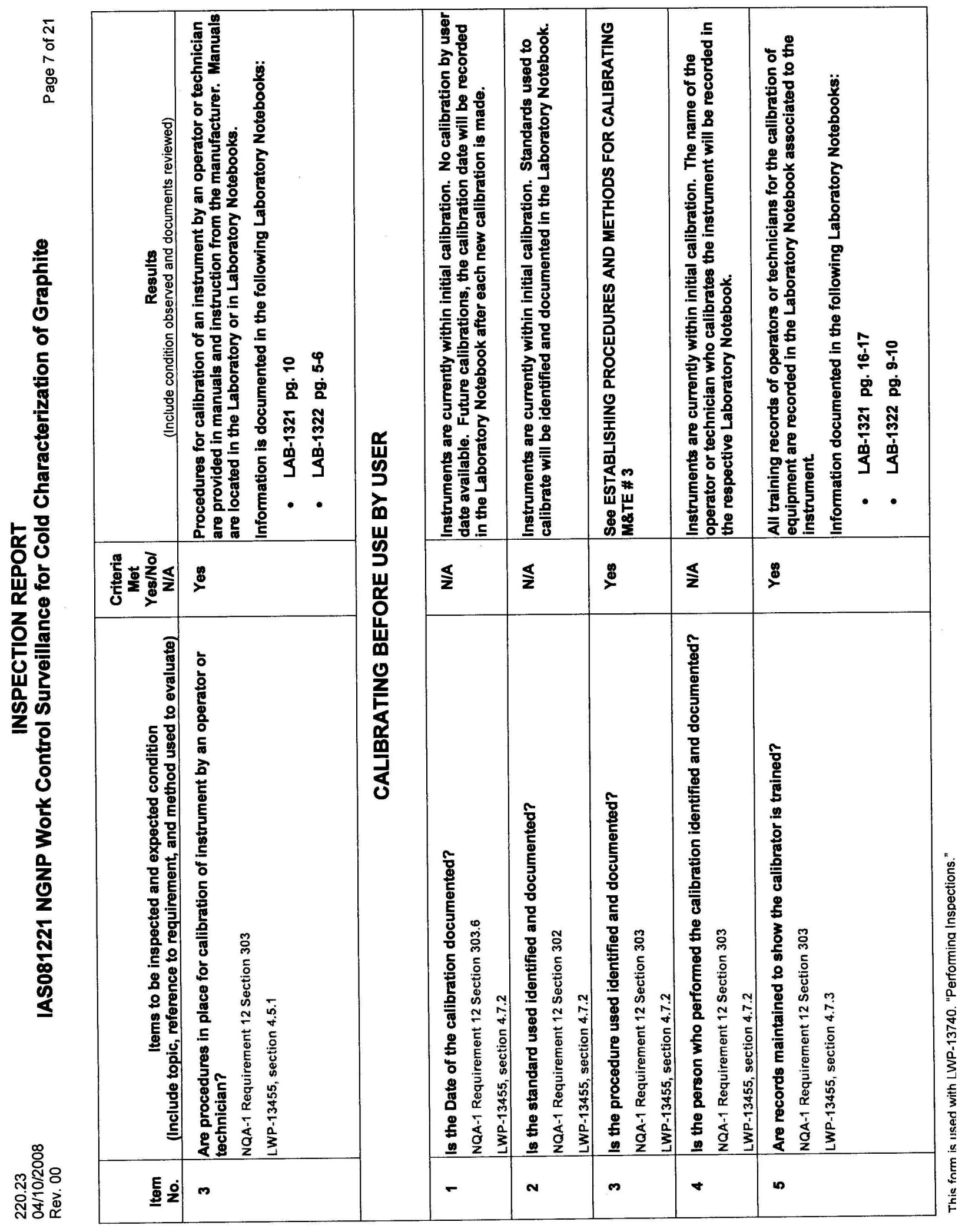




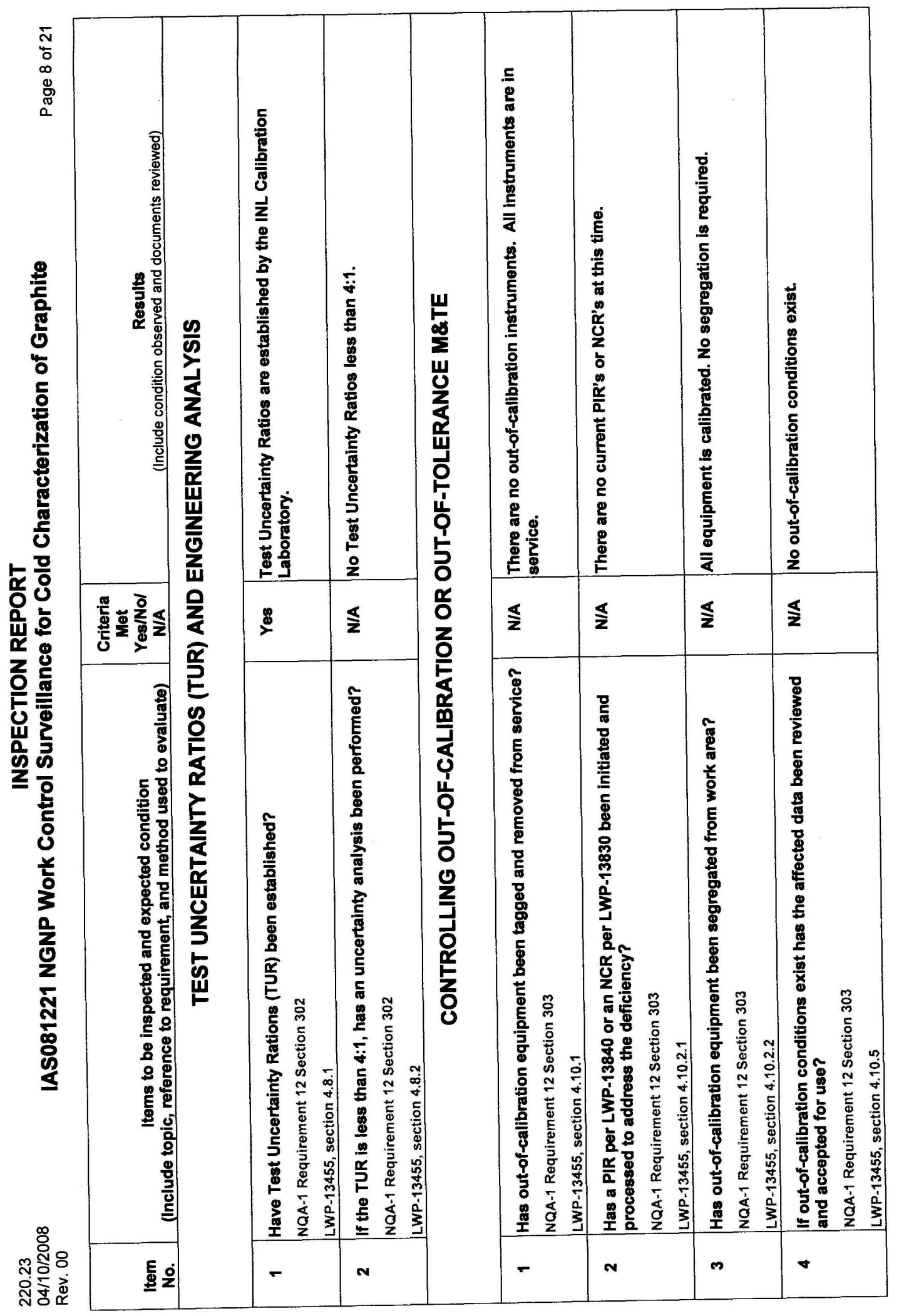




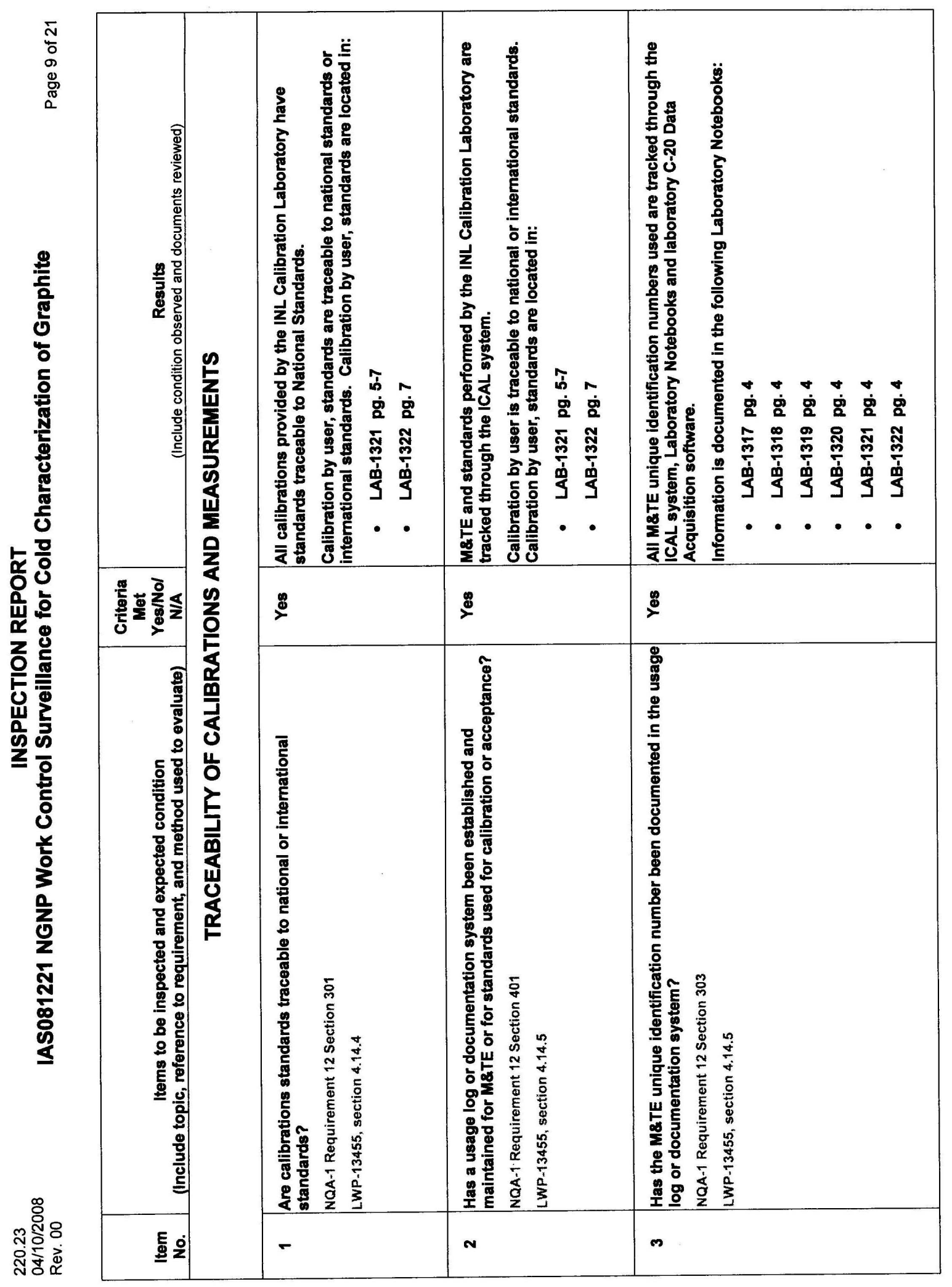

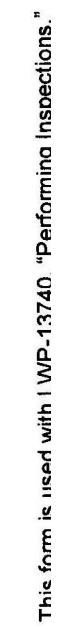




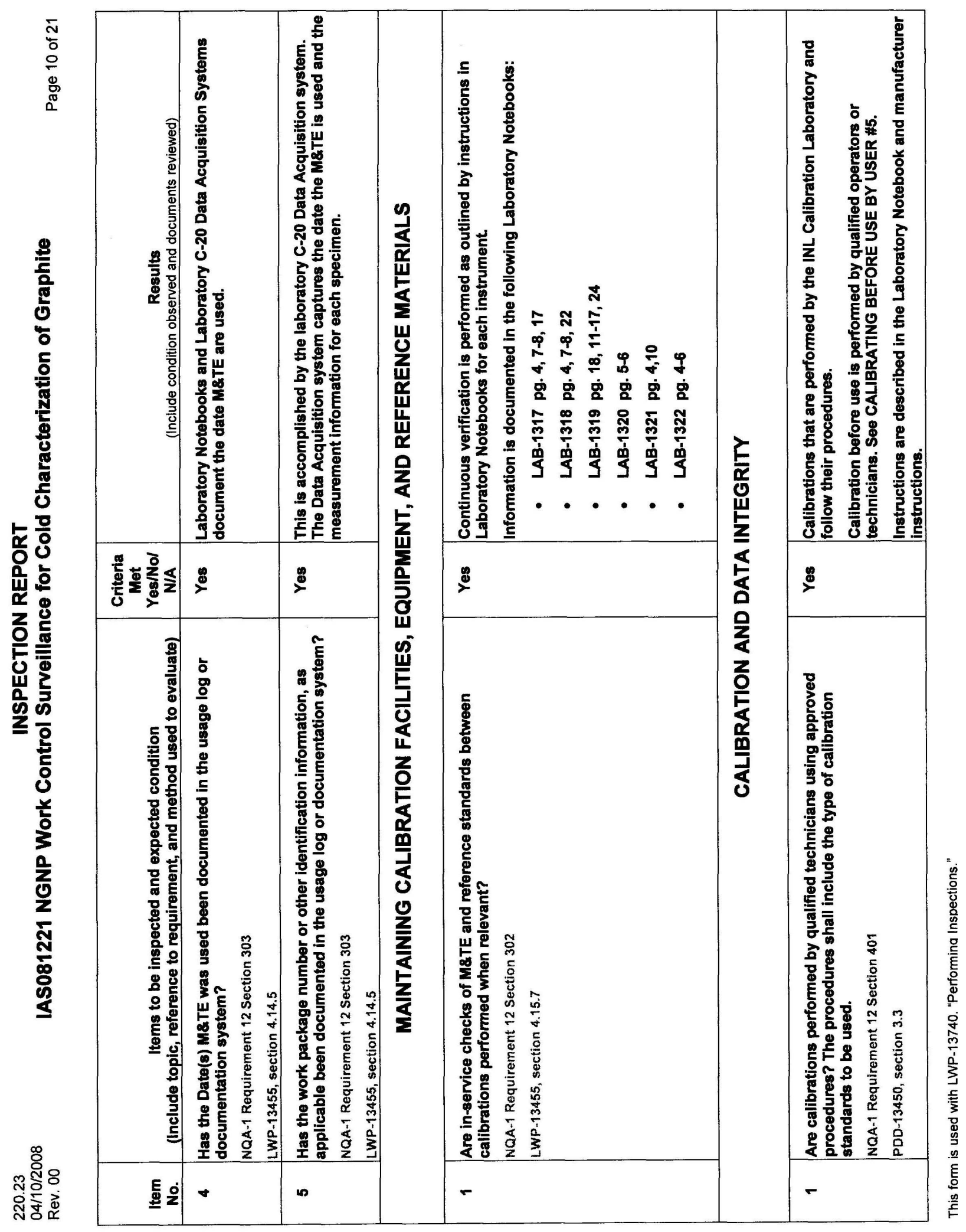




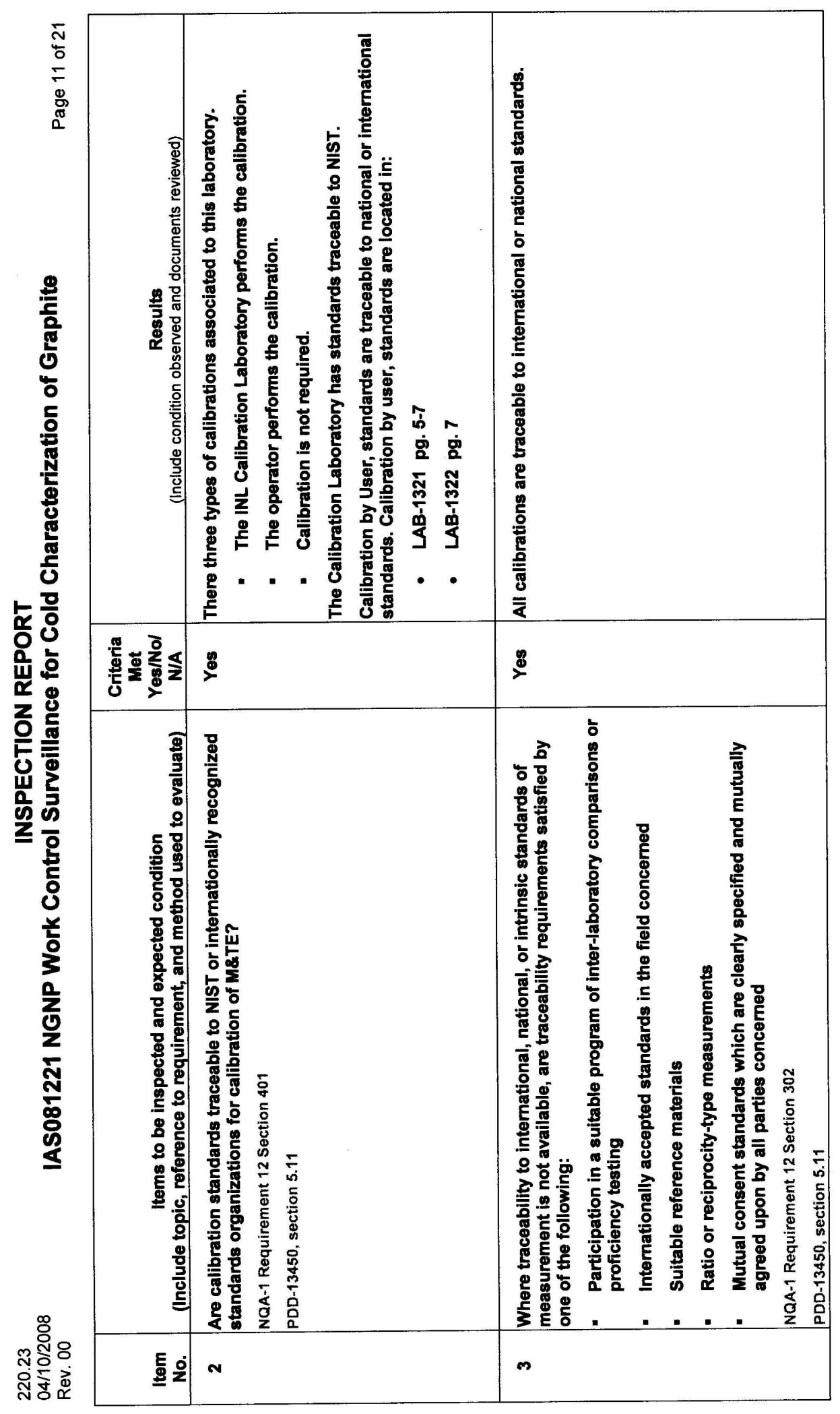




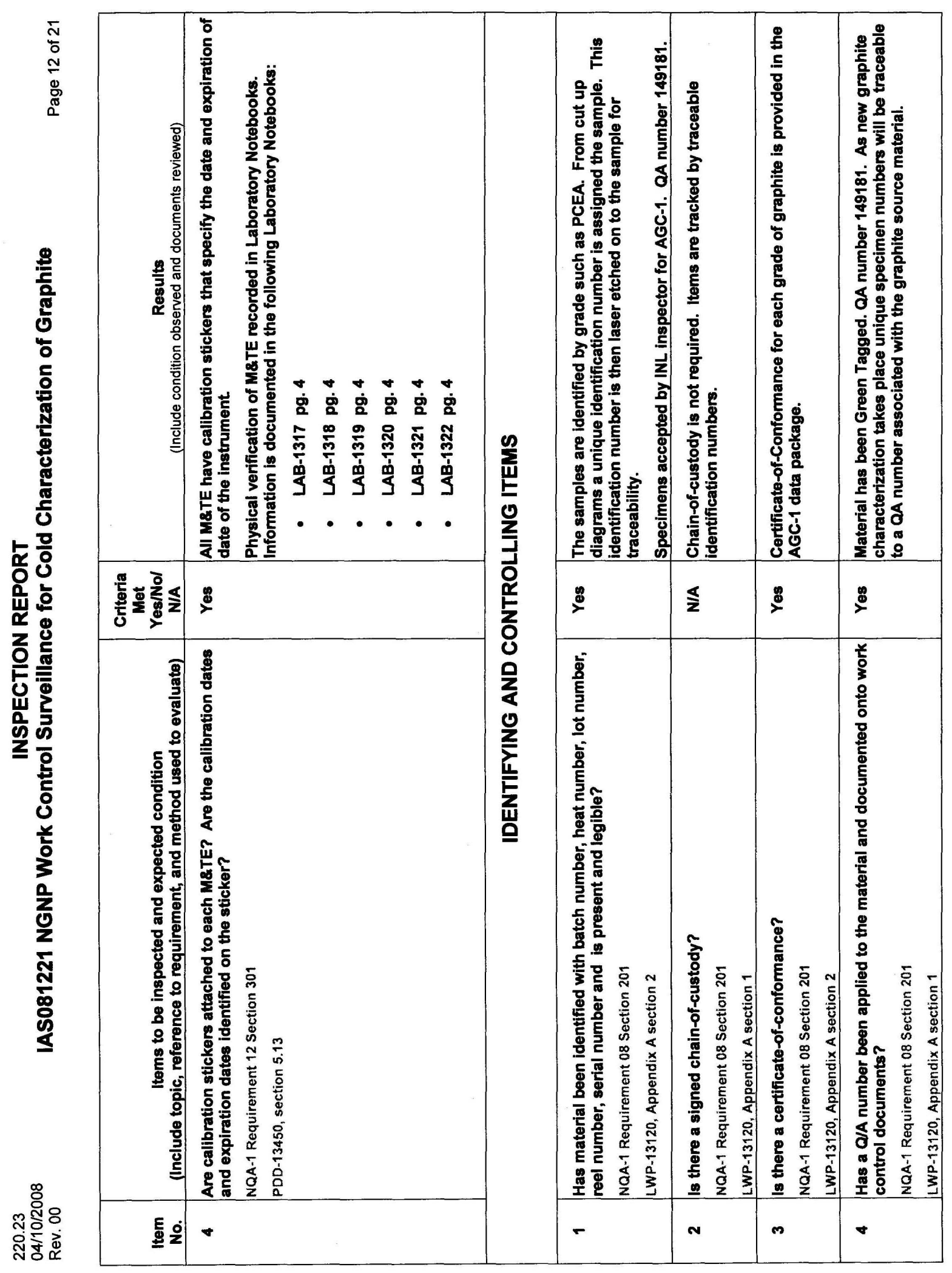

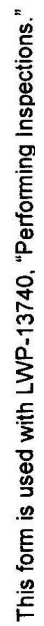




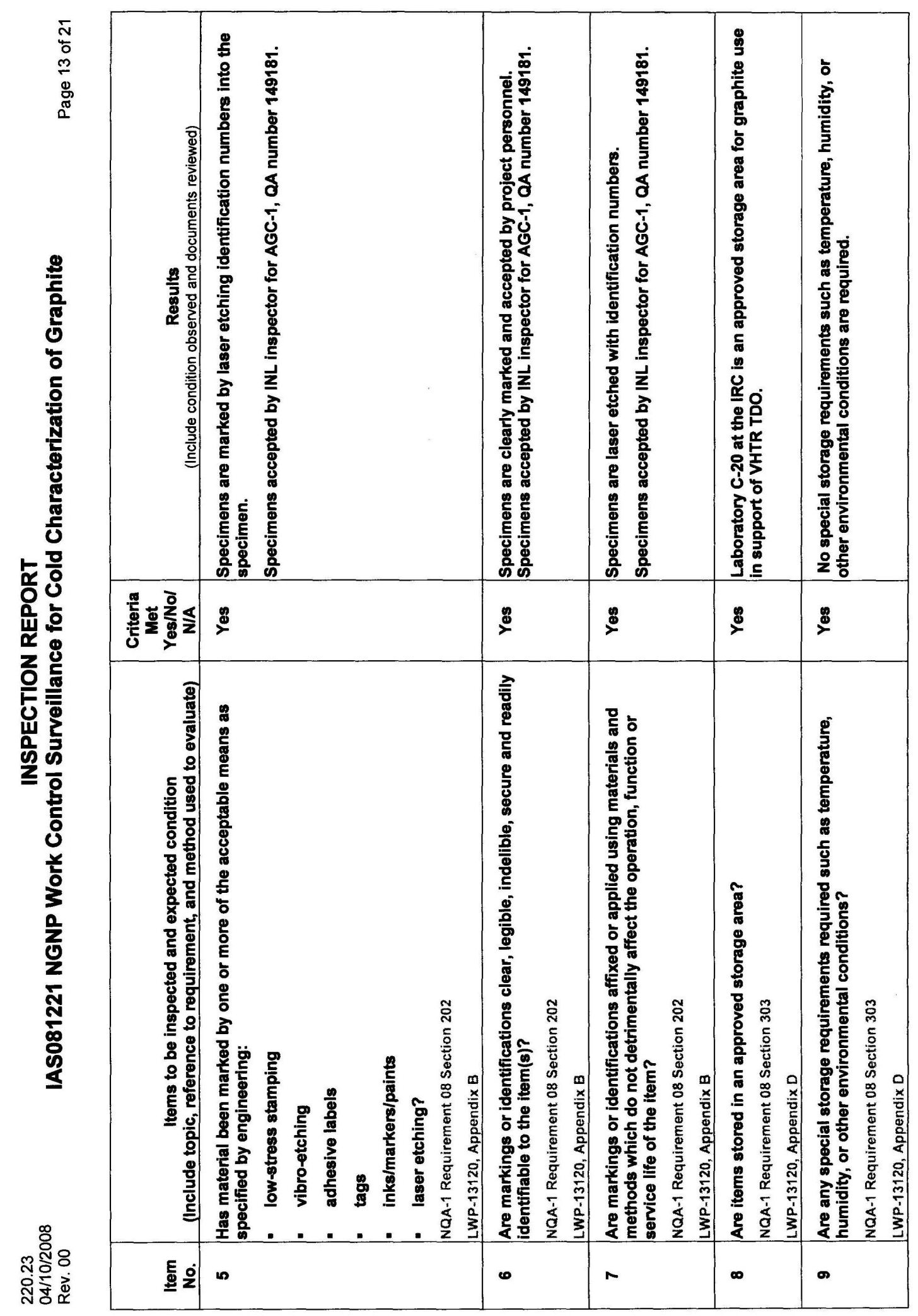

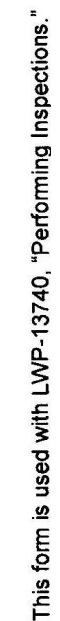




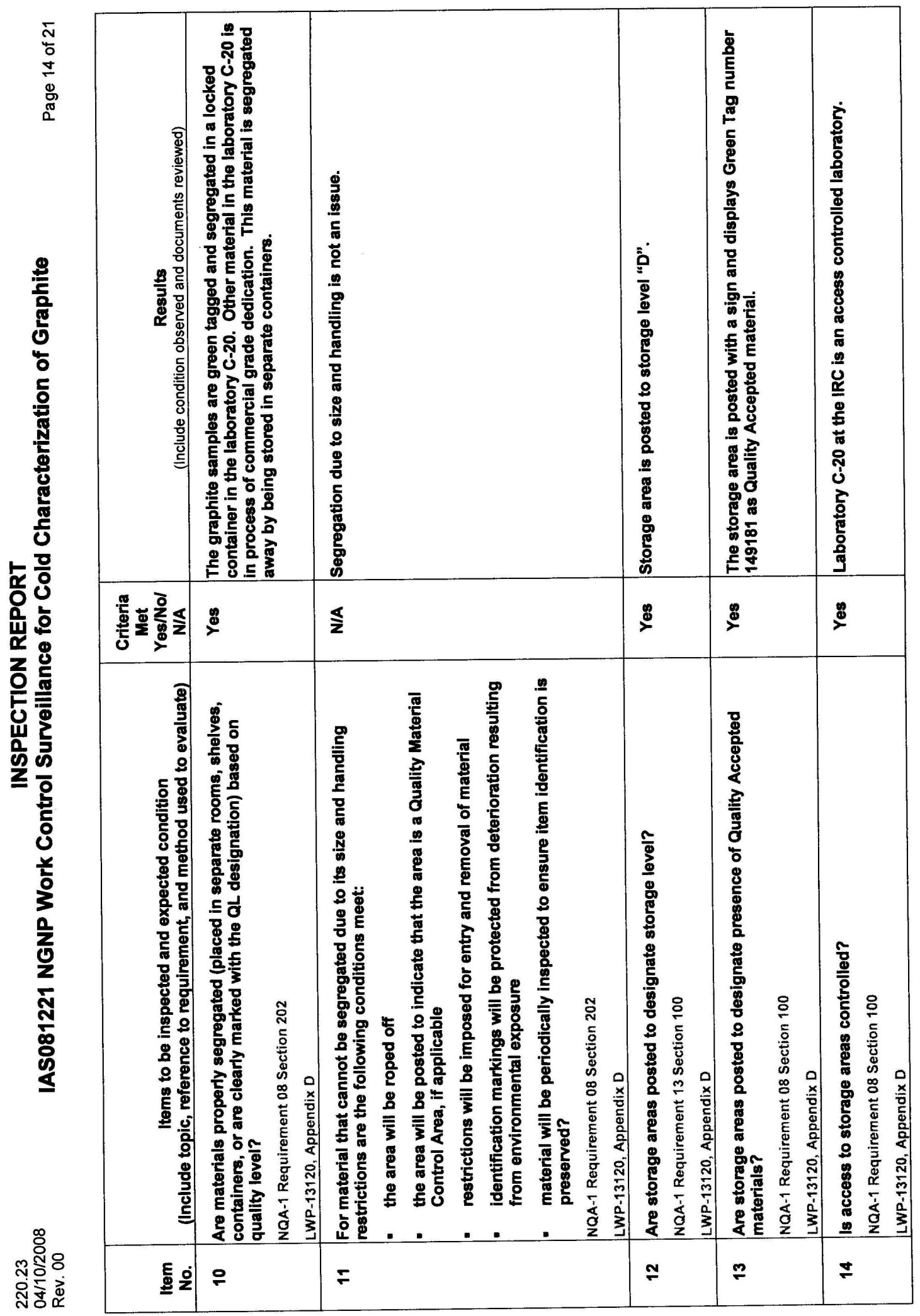

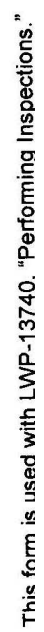




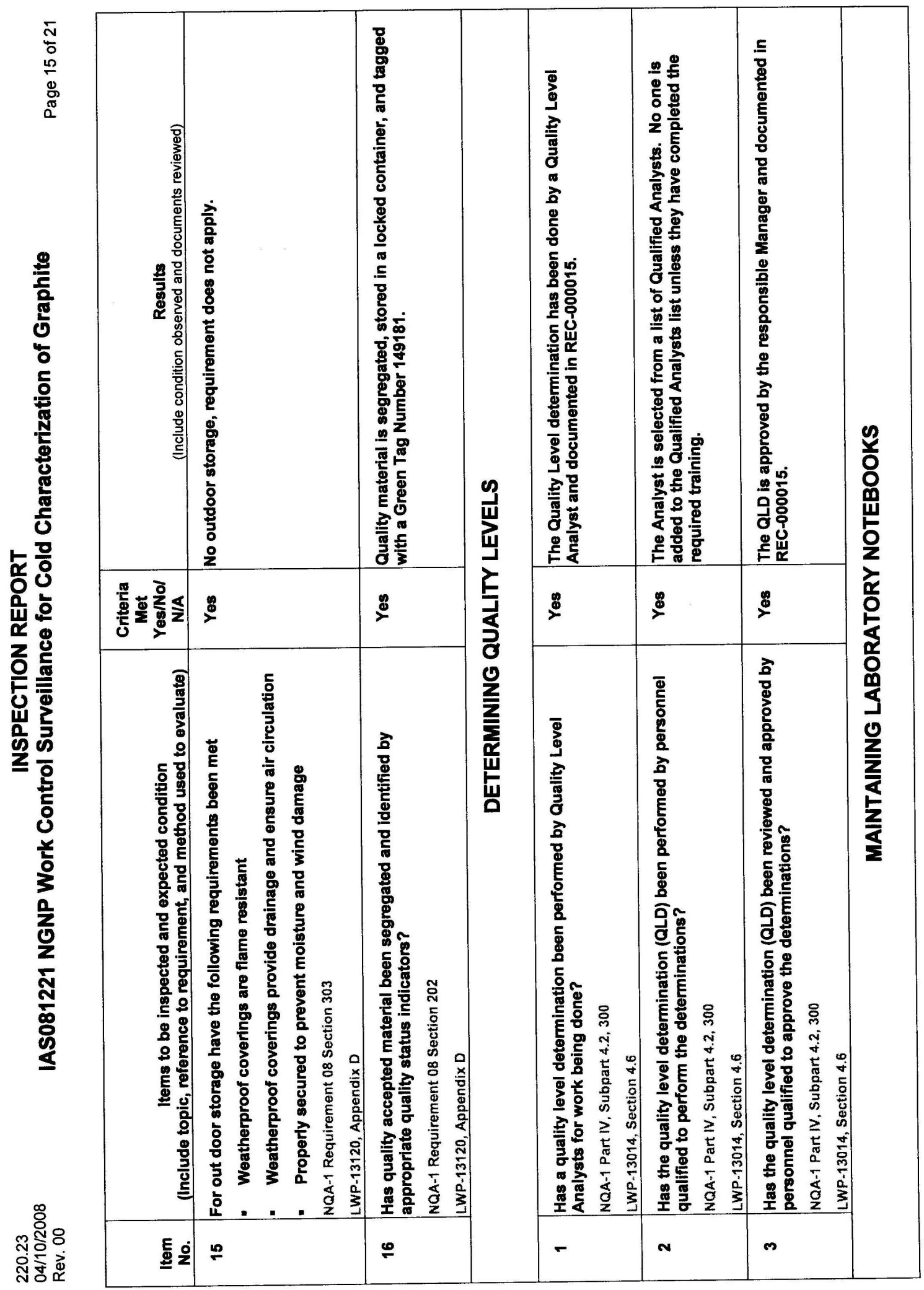

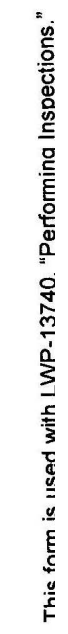




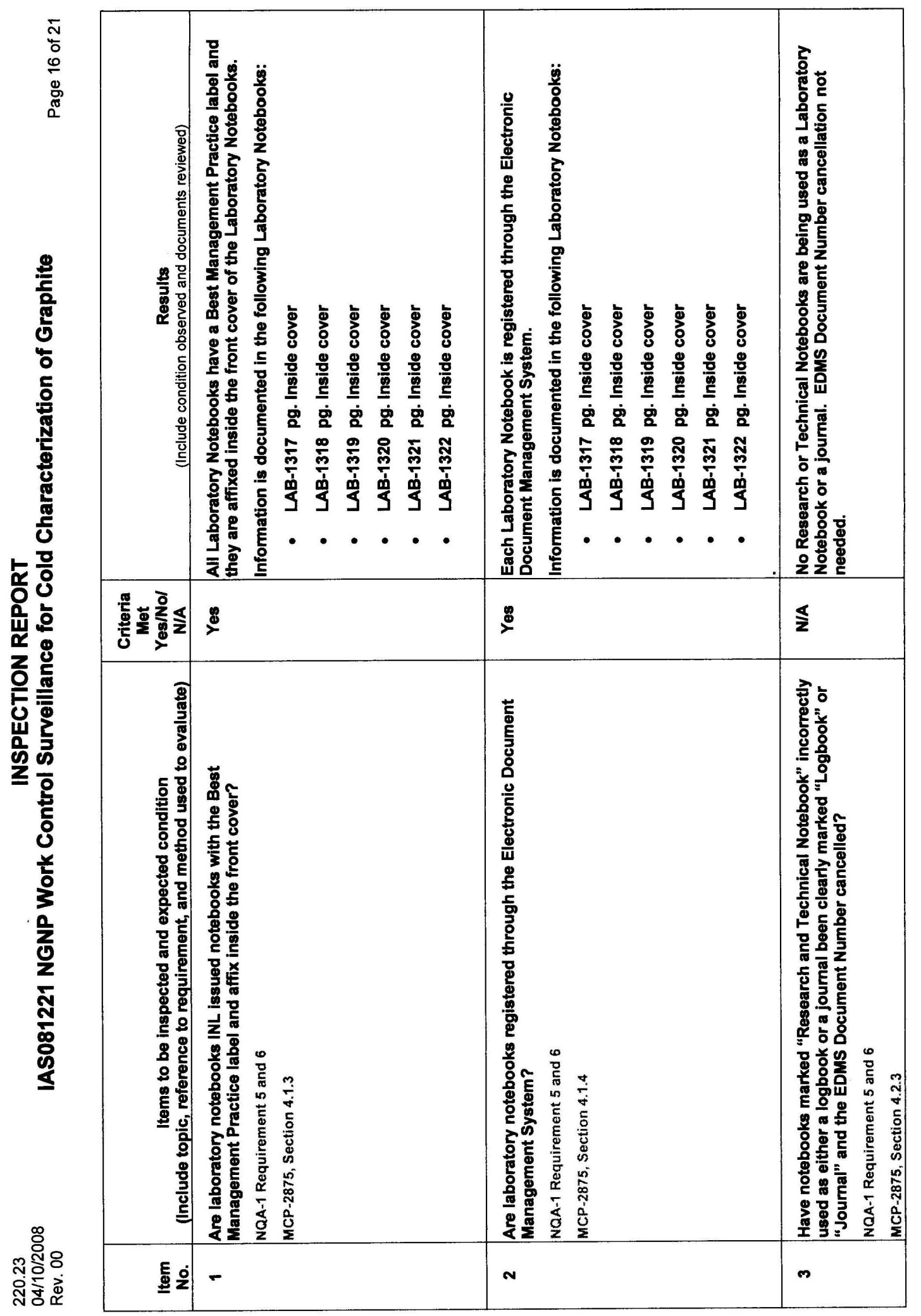

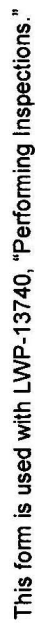




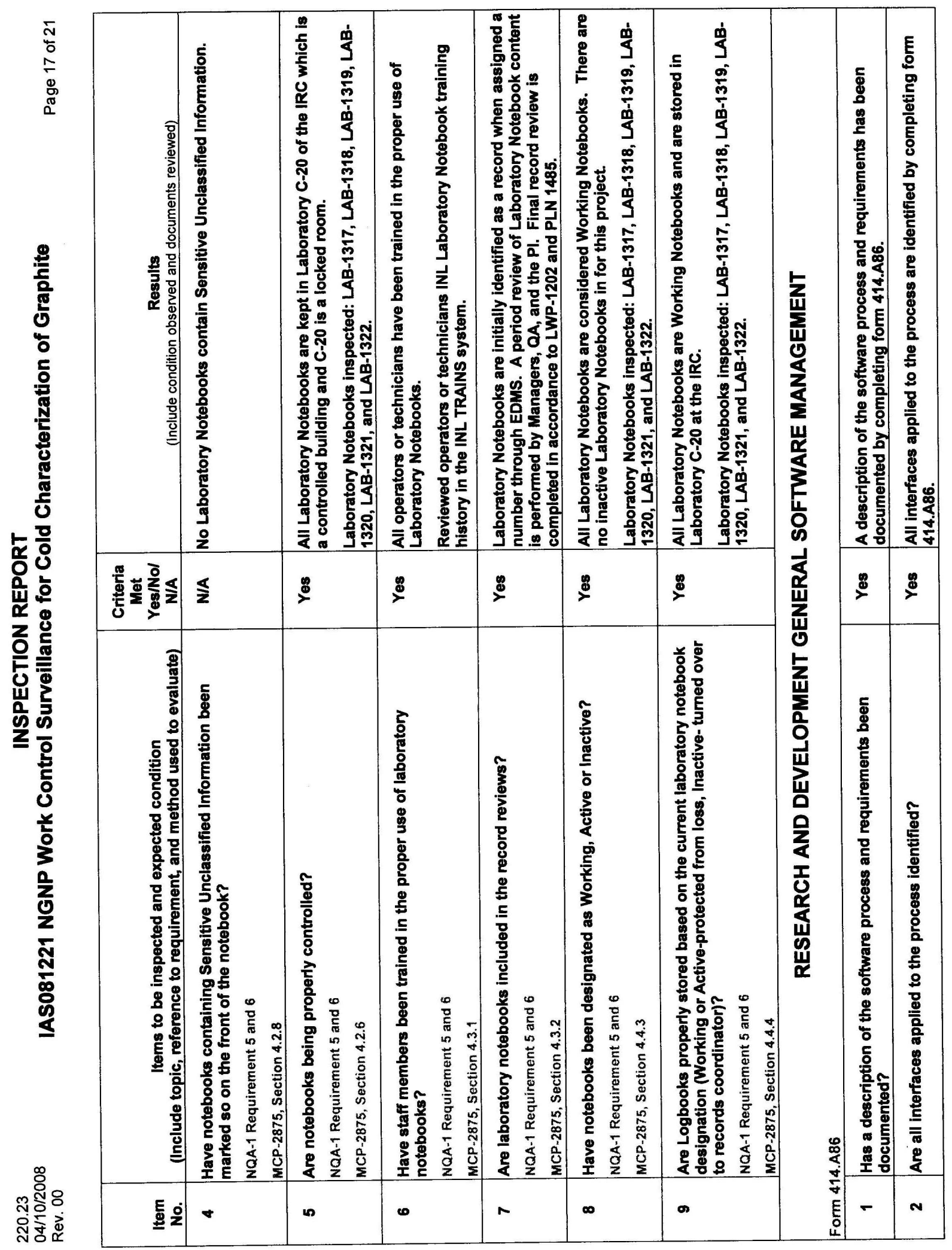




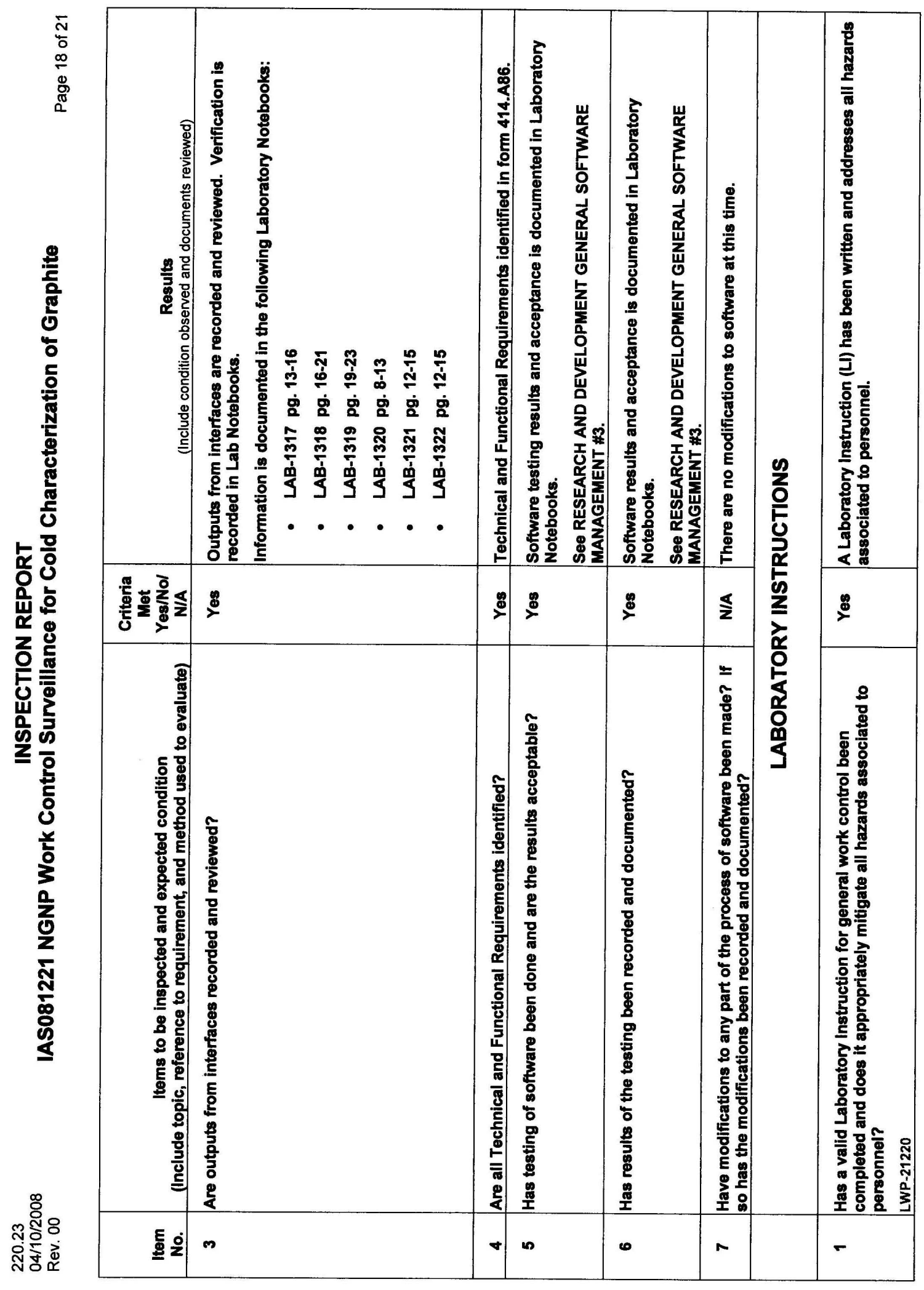

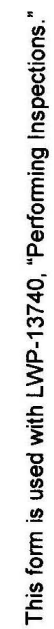




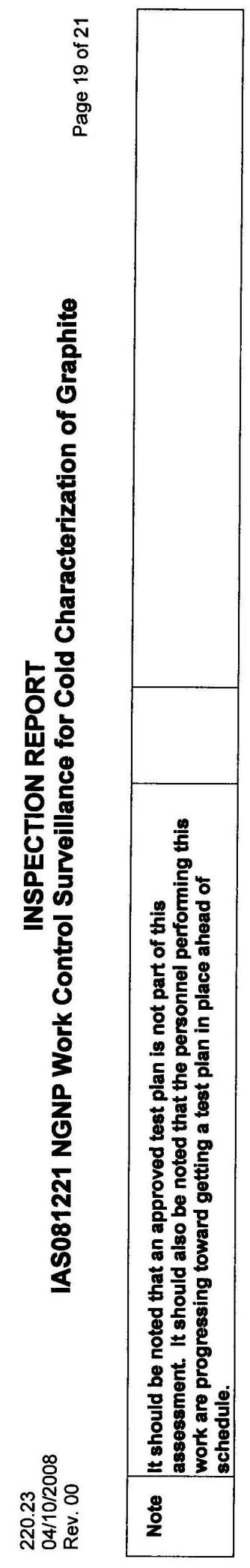




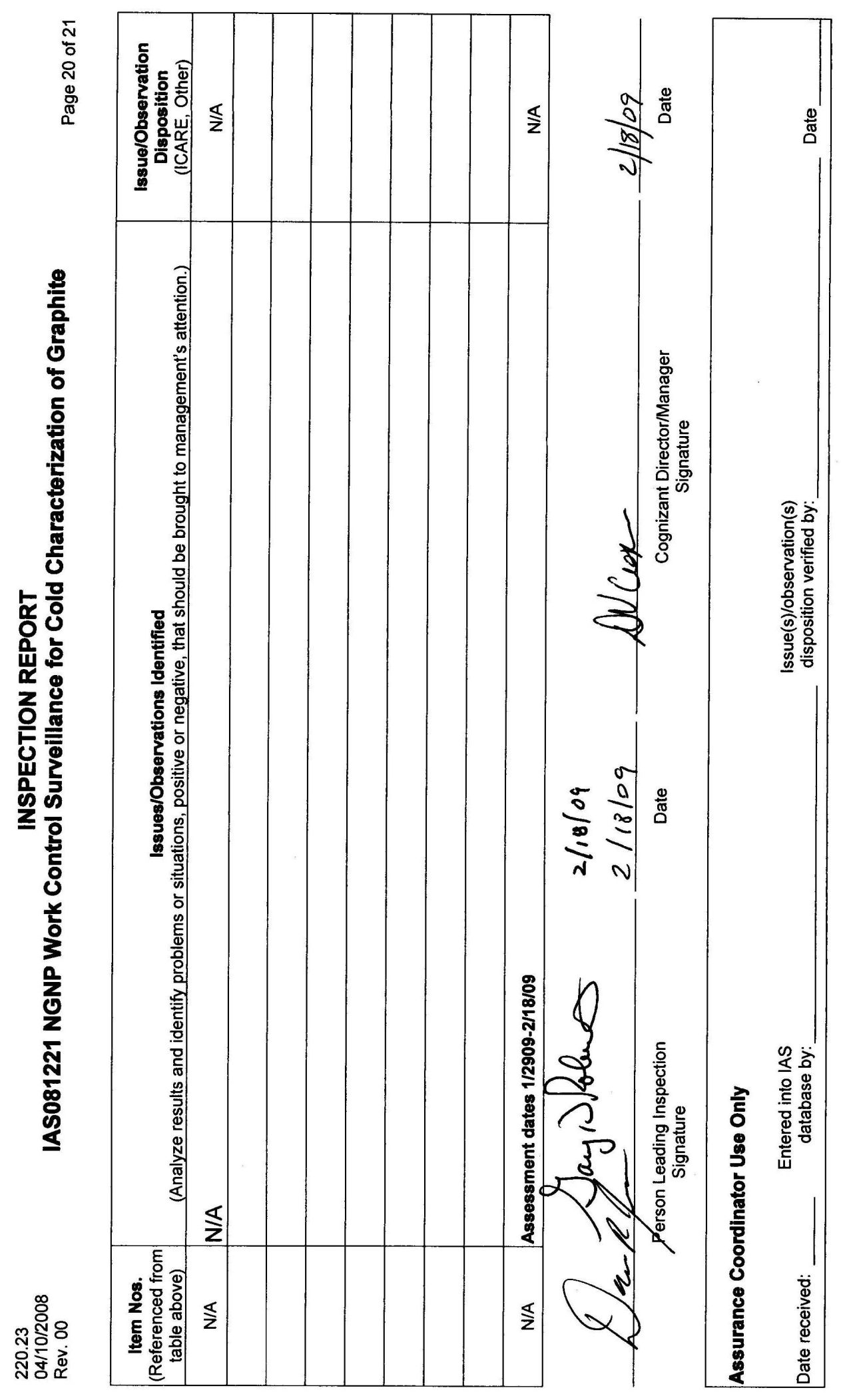

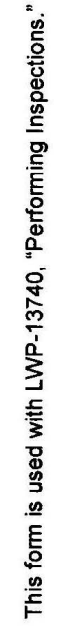




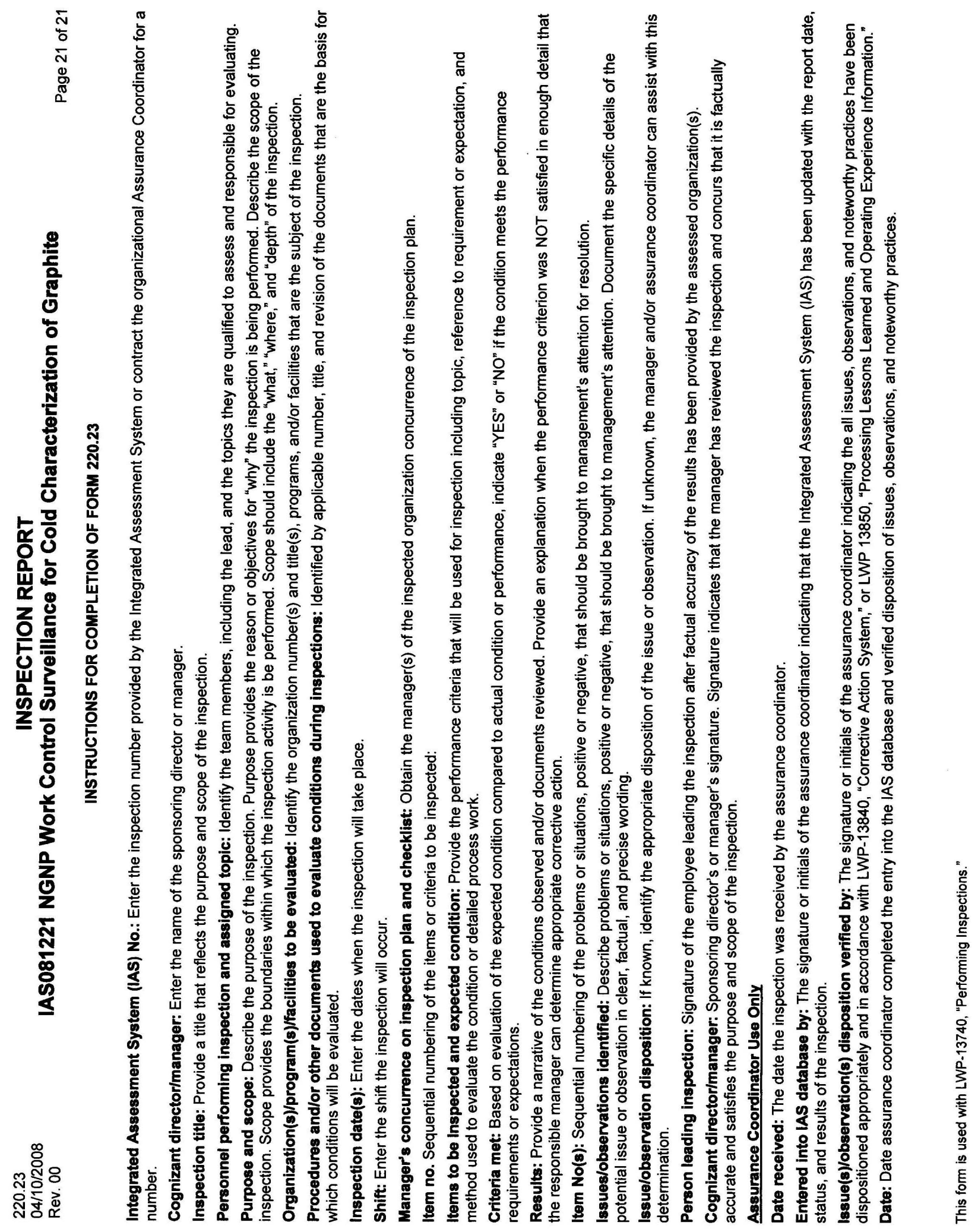


Appendix B

\section{Data Illustrating Readiness}


This page is intentionally left blank 


\section{Appendix B}

\section{Data Illustrating Readiness}

A "dress rehearsal" of all measurements was performed to demonstrate that instrumentation and methods are ready for preirradiation measurement of AGC-2 specimens. Five specimens of Poco AXM-5Q graphite were machined to a 0.5 in. diameter $\times 1.0$ in long, matching the dimensions of the AGC-2 creep sample geometry. These specimens, labeled AXM-5Q-01 through -05, were characterized at all measurement stations with the exception of the thermal diffusivity. Due to the geometrical constraints of the LFA thermal diffusivity measurement, another five specimens were machined to 0.5 in. diameter $\times 0.25 \mathrm{in}$. long. These specimens, numbered AXM-5Q-06 through -10, match the AGC-2 piggyback geometry and were used in the LFA thermal diffusivity demonstration. Table B-1 summarizes the demonstration measurements. The measurement precision is good with all having a coefficient of variation $(\mathrm{CV})$ less than $1 \%$, with the exception of the elastic modulus, calculated from the fundamental frequency, which has a $\mathrm{CV}$ of $2 \%$.

Table B-1. Summary of demonstration measurements.

\begin{tabular}{|c|c|c|c|c|c|c|}
\hline Specimen & AXM-5Q-01 & AXM-5Q-02 & AXM-5Q-03 & AXM-5Q-04 & AXM-5Q-05 & $\begin{array}{c}\text { Coefficient } \\
\text { of Variation } \\
(\%) \\
\end{array}$ \\
\hline Density (g/cc) & 1.740 & 1.736 & 1.741 & 1.740 & 1.740 & 0.13 \\
\hline CTE $\left(1 /{ }^{\circ} \mathrm{K}\right)$ & 7.680E-06 & $7.645 \mathrm{E}-06$ & 7.636E-06 & 7.723E-06 & $7.632 \mathrm{E}-06$ & 0.50 \\
\hline $\begin{array}{l}\text { Elastic modulus, } \\
\text { (sonic velocity) (Pa) }\end{array}$ & $1.280 E+10$ & $1.253 E+10$ & $1.278 \mathrm{E}+10$ & $1.281 E+10$ & $1.280 \mathrm{E}+10$ & 0.94 \\
\hline $\begin{array}{l}\text { Elastic modulus, } \\
\text { fundamental } \\
\text { frequency }[\mathrm{Pa}]\end{array}$ & $1.244 \mathrm{E}+10$ & $1.206 \mathrm{E}+10$ & $1.238 \mathrm{E}+10$ & $1.219 E+10$ & $1.184 \mathrm{E}+10$ & 2.01 \\
\hline $\begin{array}{l}\text { Electrical resistivity } \\
(\mu \mathrm{Ohm} / \mathrm{m})\end{array}$ & $1.523 E+01$ & $1.512 \mathrm{E}+01$ & $1.506 \mathrm{E}+01$ & $1.512 E+01$ & $1.506 \mathrm{E}+01$ & 0.44 \\
\hline Specimen & AXM-5Q-06 & AXM-5Q-07 & AXM-5Q-08 & AXM-5Q-09 & AXM-5Q-10 & $\begin{array}{c}\text { Coefficient } \\
\text { of Variation } \\
(\%) \\
\end{array}$ \\
\hline Density $(\mathrm{g} / \mathrm{cc})$ & 1.741 & 1.735 & 1.740 & 1.738 & 1.736 & 0.14 \\
\hline Diffusivity $\left(\mathrm{mm}^{2} / \mathrm{s}\right)$ & 25.130 & 25.307 & 25.304 & 24.927 & 24.941 & 0.74 \\
\hline
\end{tabular}

The pages that follow contain raw data samples from each measurement. 


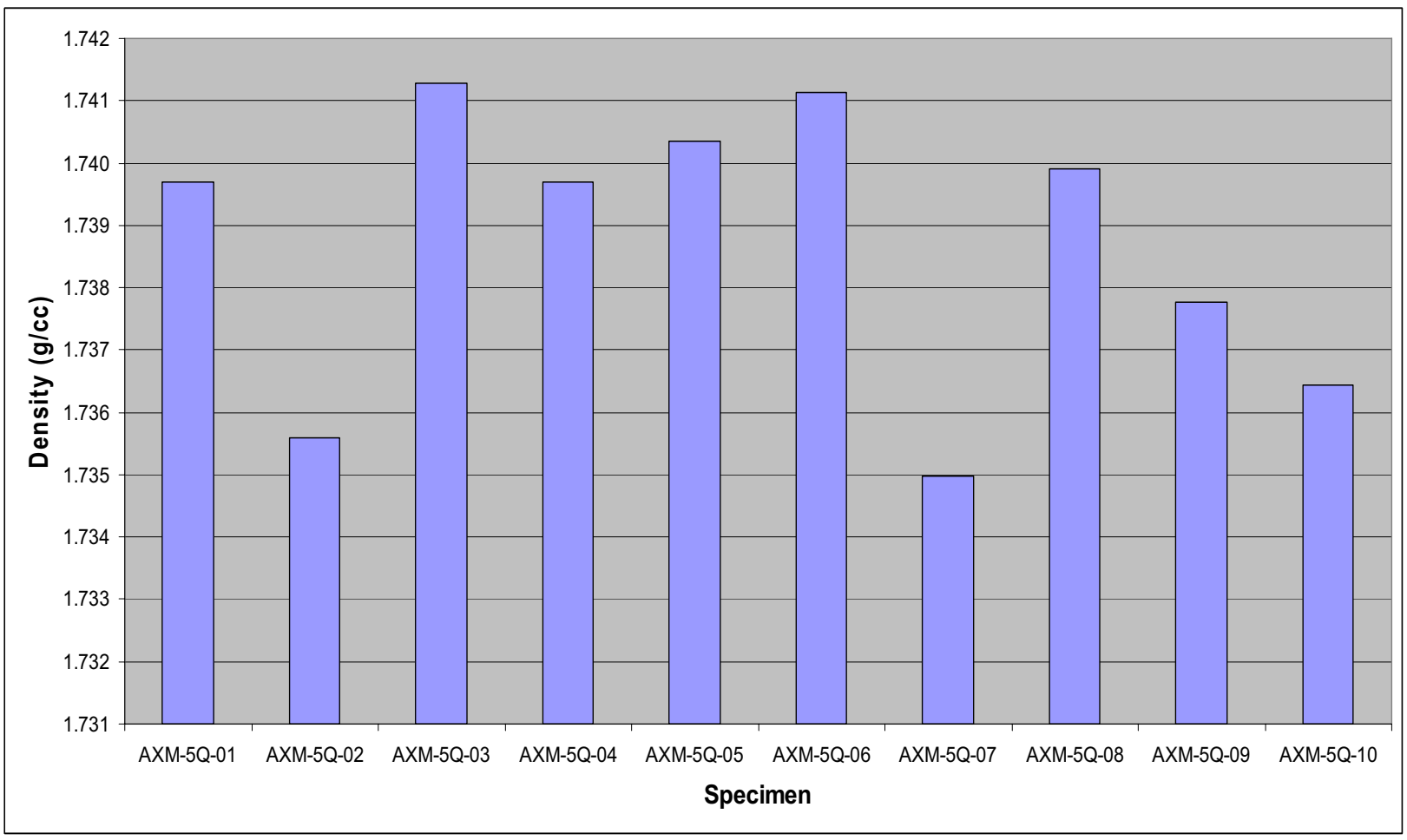




\section{Modulus by Resonant Frequency}

Specimen number

Date and Time

Operator

Sample location

mass of specimen

length of specimen

diameter of specimen

Poisson's ratio

frequency data

(specimen number

oriented up in fixture)

average resonant frequency $\quad f_{\text {avg }}$

correction factor for rod

modulus of elasticity **

$T_{1}$. correction factor

calculation of individual

terms

resultant $T_{1}$

modulus of elasticity *

Average Modulus for specimen group Standard deviation

Environmental Conditions

Temperature $\left({ }^{\circ} \mathrm{C}\right)$

Barometric Pressure (in of $\mathrm{Hg}$ )

Humidity (\%)

Sampling Plan Layout Instrument

ASTM $\mu$
AXM-5Q-01

2/17/2009 13:31

dtr

[g] 5.6264

[mm] 25.44975

[mm]
AXM-5Q-02

dtr

25.45275

12.71875
AXM-5Q-03 2

$\mathrm{dtr}$
AXM-5Q-04 AXM-5Q-05 2/17/2009 13:58 2/17/2009 14:11

$\mathrm{dtr}$

$5.6029-5.6211$

$25.49950 \quad 25.47800$

$12.68113-12.70475$

0.1667

0.1667

0.1667

0.1667

\begin{tabular}{r|r|r|r|r|r|}
\cline { 2 - 5 } 2 & 32400 & 32200 & 32300 & 31000 \\
\hline 3 & 32400 & 31800 & 32300 & 32300 & 30900 \\
\hline 4 & 31500 & 31300 & 31500 & 32300 & 31300 \\
\hline 3 & 32400 & 32300 & 32300 & 32300 & 32300 \\
\hline 7 & 32400 & 32200 & 29500 & 30400 \\
\hline 8 & 32400 & 31900 & 32200 & 29600 & 32000 \\
\hline 10 & 32400 & 31900 & 32300 & 32300 & 32300 \\
\hline 32400 & 32000 & 32200 & 32300 & 32300 \\
\hline 31500 & 31700 & 30300 & 32300 & 32300 \\
\hline 32400 & 32300 & 32000 & 32300 & 31400 \\
\hline 3220 & 31750 & 31950 & 31750 & 31620 \\
\hline
\end{tabular}

$[\mathrm{Hz}]$

$\mathrm{T}_{1}{ }^{\prime}$

2.105274156

2.10481668

2.096761759

2.095147081

2.06500756

E

12439685556

12056617580

12376697176

12190187913

11836848208

$\begin{array}{lllll}2.277084311 & 2.276507264 & 2.266351933 & 2.264317327 & 2.228119442\end{array}$

$\begin{array}{llllll}0.030473207 & 0.030445675 & 0.029963177 & 0.029866972 & 0.030191861\end{array}$

$\begin{array}{lllll}0.320291243 & 0.320001863 & 0.314930527 & 0.313919363 & 0.290047144\end{array}$

$\begin{array}{lllll}2.266153666 & 2.265581558 & 2.255513147 & 2.253495955 & 2.182117803\end{array}$

$\mathrm{T}_{1}$

2.105274156

2.10481668

2.096761759

2.095147081

2.06500756

$[\mathrm{Pa}]$

$1.21 \mathrm{E}+10$

$1.24 \mathrm{E}+10$

$1.22 \mathrm{E}+10$

$1.22 \mathrm{E}+10$

$2.19 \mathrm{E}+08$

$\begin{array}{lllll}22.2{ }^{\prime} \mathrm{C} & 22.2^{\prime} \mathrm{C} & 22.1 \mathrm{C}^{\mathrm{C}} & 22.1 \mathrm{C}^{\mathrm{C}} & 22.3 \mathrm{'} \mathrm{C} \\ 24.99 \mathrm{inHg} & 24.98 \mathrm{inHg} & 24.98 \mathrm{inHg} & 24.98 \mathrm{inHg} & 24.93 \mathrm{inHg} \\ 19.9 \% \mathrm{RH} & 19.9 \% \mathrm{RH} & 20.2 \% \mathrm{RH} & 20.4 \% \mathrm{RH} & 20.3 \% \mathrm{RH}\end{array}$

$100 \%$ sampling, test them all

Grindosonic MK5i

C 747 - 93 Reapproved 2005

Using Equation 5 \& 6 in ASTM C 1259 - 08

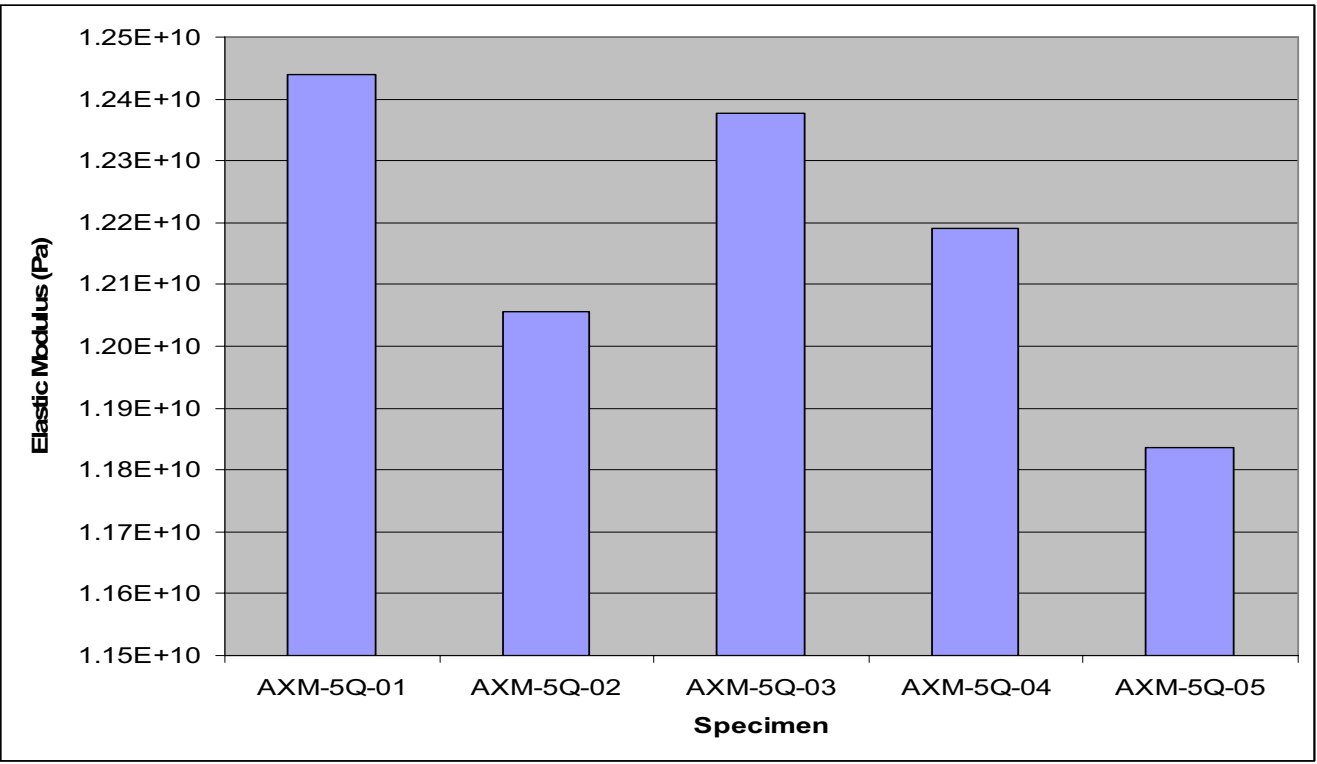




\section{Resistivity}

Specimen Number

Date and Time

Operator

Sample Location

Applied current, I

Compl. Voltage

ID Orientation:

Forward current:

Voltage readings, $\mathrm{mV}$

Resistance readings, $\Omega$

Reverse current:

Voltage readings, $\mathrm{mV}$

Resistance readings, $\Omega$

End-for-end orientation:

Reverse current:

Voltage readings, $\mathrm{mV}$

Resistance readings, $\Omega$

Forward current:

Voltage readings, $\mathrm{mV}$

Resistance readings, $\Omega$

Average voltage, $\mathrm{V}$

Average resistance, $\mathrm{R}=\mathrm{V} / \mathrm{I}$

Potential Contact Distance, L

Average area, $\mathbf{A} \mathrm{mm}^{2}$ *

Resistivity, $p=\left(R^{\star} A\right) / L$

Environmental Condition

Temperature (Deg C)

Barometric Pressure (in $\mathrm{Hg}$ )

Humidity $(\%)$

Other Test Information

Specimen Orientation

Method of Measuring Resistance

Probe Location

Instruments

ASTM

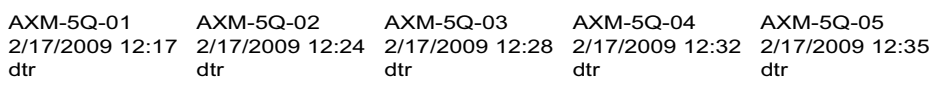

$\begin{array}{llllll}\mathrm{mA} & 4.0000 & 4.0000 & 4.0000 & 4.0000 & 4.0000 \\ \mathrm{~V} & 2.5000 & 2.5000 & 2.5000 & 2.5000 & 2.5000\end{array}$

\begin{tabular}{|l|r|r|r|r|r|}
\hline & 0.006141 & 0.006432 & 0.006426 & 0.006496 & 0.006102 \\
\hline 2 & 0.006522 & 0.00618 & 0.006232 & 0.006584 & 0.006259 \\
\hline 4 & 0.006096 & 0.006368 & 0.00629 & 0.00587 & 0.006099 \\
\hline
\end{tabular}

\begin{tabular}{|l|l|l|l|l|l|}
\cline { 2 - 6 } 1 & 0.001535 & 0.001608 & 0.001607 & 0.001624 & 0.001526 \\
\hline & 0.001631 & 0.001545 & 0.001558 & 0.001646 & 0.001565 \\
\hline & 0.001524 & 0.001592 & 0.001572 & 0.001468 & 0.001525 \\
\hline
\end{tabular}

\begin{tabular}{|l|l|l|l|l|l|}
\hline & -0.006015 & -0.005245 & -0.005757 & -0.005953 & -0.006073 \\
\hline & -0.006254 & -0.006168 & -0.005696 & -0.006351 & -0.006084 \\
\hline-0.005802 & -0.006041 & -0.005752 & -0.005649 & -0.005782 \\
\hline & -0.005792 & -0.005779 & -0.005969 & -0.005654 & -0.005903 \\
\hline
\end{tabular}

\begin{tabular}{|l|r|r|r|r|r|r|}
\hline & 0.001504 & 0.001311 & 0.001439 & 0.001488 & 0.001518 \\
\hline 2 & 0.001564 & 0.001542 & 0.001424 & 0.001588 & 0.001521 \\
\hline 3 & 0.001451 & 0.00151 & 0.001438 & 0.001412 & 0.001446 \\
\hline
\end{tabular}
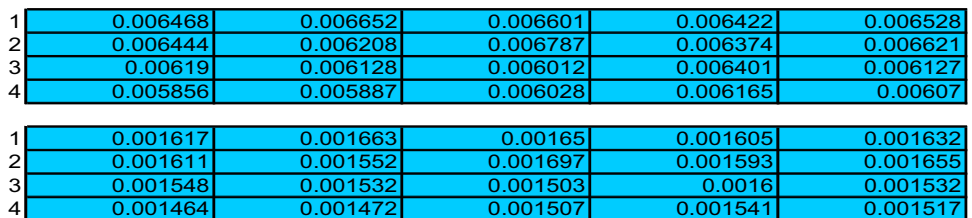

\begin{tabular}{|l|r|r|r|r|r|}
\hline & -0.005671 & -0.00572 & -0.005465 & -0.005837 & -0.005573 \\
\hline 2 & -0.006225 & -0.006298 & -0.006275 & -0.005919 & -0.00619 \\
\hline & -0.005768 & -0.005411 & -0.005532 & -0.005556 & -0.005475 \\
\hline
\end{tabular}

\begin{tabular}{|c|c|c|c|c|c|}
\hline & 0.001418 & $\begin{array}{l}0.00143 \\
\end{array}$ & 0.001366 & 0.001459 & 0.001393 \\
\hline 2 & 0.001556 & 0.001575 & 0.001569 & 0.00148 & 0.001548 \\
\hline & 0.001442 & 0.001353 & 0.001383 & 0.001389 & 0.001369 \\
\hline & 0.001508 & 0.001489 & 0.001377 & 0.001515 & 0.001422 \\
\hline IV & 0.006087 & 0.006044 & 0.006034 & 0.006082 & 0.006035 \\
\hline $\mathrm{m} \Omega$ & 1.521813 & 1.511063 & 1.508438 & 1.520438 & 1.508938 \\
\hline
\end{tabular}

$\mathrm{mm}$

12.7

12.7

12.7

12.7

12.7

$\mathrm{mm}^{2}$

127.0787

127.0512

126.8265

126.3006

126.7716

$\mu \Omega / m$

15.23

15.12

15.06

15.12

15.06

\begin{tabular}{|c|c|c|c|c|}
\hline $22.2^{\prime} \mathrm{C}$ & $22.22{ }^{\prime} \mathrm{C}$ & $22.2^{\prime} \mathrm{C}$ & $22.2^{\prime} \mathrm{C}$ & $22.2^{\prime} \mathrm{C}$ \\
\hline $24.96 \mathrm{inHg}$ & $24.97 \mathrm{inHg}$ & $24.97 \mathrm{inHg}$ & $24.97 \mathrm{inHg}$ & $24.96 \mathrm{in} \mathrm{Hg}$ \\
\hline $19.9 \% \mathrm{RH}$ & $19.9 \% \mathrm{RH}$ & $19 / 9 \% \mathrm{RH}$ & $19.9 \% \mathrm{RH}$ & $19.8 \% \mathrm{RH}$ \\
\hline $\begin{array}{l}\text { horizontal } \\
\text { voltmeter } \\
\text { location }\end{array}$ & $\begin{array}{l}\text { horizontal } \\
\text { voltmeter } \\
\text { location }\end{array}$ & $\begin{array}{l}\text { horizontal } \\
\text { voltmeter } \\
\text { location }\end{array}$ & $\begin{array}{l}\text { horizontal } \\
\text { voltmeter } \\
\text { location }\end{array}$ & $\begin{array}{l}\text { horizontal } \\
\text { voltmeter } \\
\text { location }\end{array}$ \\
\hline
\end{tabular}

Keithley Model 2182 Nanovoltmeter

Keithley Model 6220 DC Current Source

C 611 - 98 Reapproved 2005 


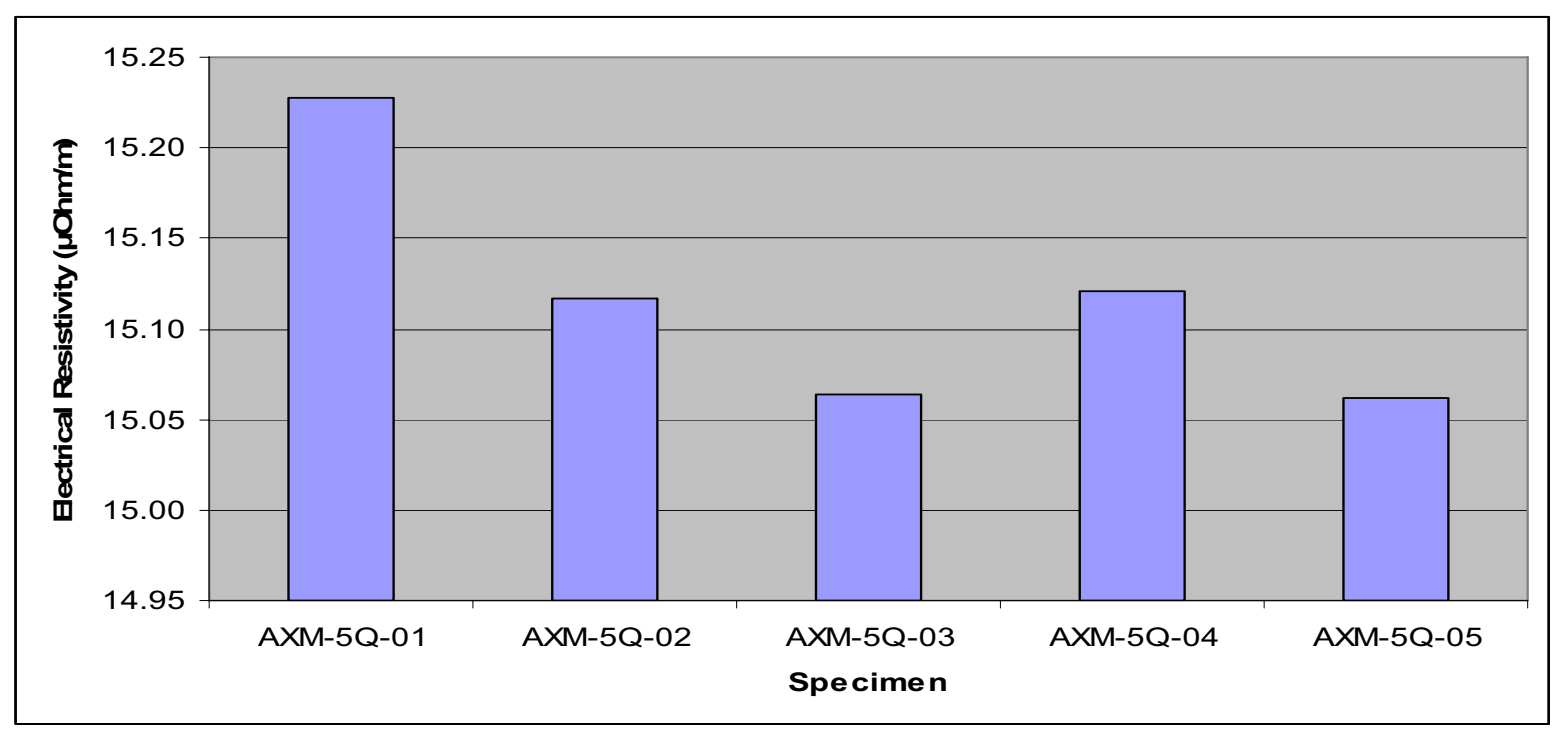


Young's Modulus, Shear Modulus and Poisson's Ratio by Sonic Velocity

\begin{tabular}{|c|c|c|c|c|c|}
\hline Specimen Number & AXM-5Q-01 & AXM-5Q-02 & AXM-5Q-03 & AXM-5Q-04 & AXM-5Q-05 \\
\hline Date and Time & 2/19/2009 13:33 & 2/19/2009 13:39 & 2/19/2009 13:48 & 2/19/2009 13:58 & 2/19/2009 14:03 \\
\hline Operator & wds & wds & wds & wds & wds \\
\hline \multicolumn{6}{|l|}{ Specimen Location } \\
\hline Specimen Length, m & 0.02545 & 0.025453 & 0.025532 & 0.0255 & 0.025478 \\
\hline Density, $\rho \mathrm{kg} / \mathrm{m}^{3}$ & 1739.6972 & 1735.5978 & 1741.2863 & 1739.6932 & 1740.3514 \\
\hline Longitudinal Traverse Time, $\mathbf{s}$ & $8.58 \mathrm{E}-06$ & 8.56E-06 & 8.61E-06 & 8.54E-06 & $8.58 \mathrm{E}-06$ \\
\hline Shear Traverse Time, $\mathbf{s}$ & $1.52 \mathrm{E}-05$ & $1.54 \mathrm{E}-05$ & $1.52 \mathrm{E}-05$ & $1.52 \mathrm{E}-05$ & $1.52 \mathrm{E}-05$ \\
\hline $\begin{array}{l}\text { Longitudinal Zero Correction, } \\
\mathbf{s}\end{array}$ & $1.89 \mathrm{E}-07$ & $1.89 \mathrm{E}-07$ & $1.89 \mathrm{E}-07$ & $1.89 \mathrm{E}-07$ & $1.89 \mathrm{E}-07$ \\
\hline Shear Zero Correction, s & 2.10E-07 & 2.10E-07 & 2.10E-07 & 2.10E-07 & 2.10E-07 \\
\hline $\begin{array}{l}\text { Sonic Velocities, } v_{1}(\mathrm{~m} / \mathrm{s}) \\
\text { Longitudinal }\end{array}$ & $3.035 \mathrm{E}+03$ & $3.041 \mathrm{E}+03$ & $3.032 \mathrm{E}+03$ & $3.054 \mathrm{E}+03$ & $3.037 \mathrm{E}+03$ \\
\hline $\begin{array}{l}\text { Sonic Velocities, } \mathrm{v}_{\mathrm{s}}(\mathrm{m} / \mathrm{s}) \\
\text { Shear }\end{array}$ & $1.701 \mathrm{E}+03$ & $1.679 \mathrm{E}+03$ & $1.699 \mathrm{E}+03$ & $1.699 \mathrm{E}+03$ & $1.701 \mathrm{E}+03$ \\
\hline Elastic Modulus, $[\mathrm{Pa}] \mathrm{E}=\rho v_{1}^{2}$ & $1.60228 \mathrm{E}+10$ & $1.60462 \mathrm{E}+10$ & $1.60071 \mathrm{E}+10$ & 1.62209E+10 & 1.60527E+10 \\
\hline Shear Modulus, $[\mathrm{Pa}] \mathrm{G}=\rho \mathrm{v}_{\mathrm{s}}{ }^{2}$ & $5.035 \mathrm{E}+09$ & $4.892 \mathrm{E}+09$ & $5.025 \mathrm{E}+09$ & $5.021 \mathrm{E}+09$ & $5.034 \mathrm{E}+09$ \\
\hline $\begin{array}{l}\text { Poisson's Ratio } \mu=(1- \\
\left.\left[2\left(v_{s} / v_{1}\right)^{2}\right]\right) /\left(2-\left[2\left(v_{s} / v_{l}\right)^{2}\right]\right)\end{array}$ & $2.709 \mathrm{E}-01$ & 2.807E-01 & $2.712 \mathrm{E}-01$ & $2.758 \mathrm{E}-01$ & $2.715 \mathrm{E}-01$ \\
\hline $\begin{array}{l}\text { Elastic Modulus, [Pa] } \\
E=\rho v_{1}^{2}[(1+\mu)(1-2 \mu) /(1-\mu)]\end{array}$ & $1.280 \mathrm{E}+10$ & 1.253E+10 & $1.278 \mathrm{E}+10$ & $1.281 \mathrm{E}+10$ & $1.280 \mathrm{E}+10$ \\
\hline Temperature (Deg C) & 21.8 'C & $21.8^{\prime} \mathrm{C}$ & $21.8^{\prime} \mathrm{C}$ & 21.8 'C & $21.8^{\prime} \mathrm{C}$ \\
\hline Pressure (in of $\mathrm{Hg}$ ) & $24.8 \mathrm{inHg}$ & $24.8 \mathrm{inHg}$ & $24.8 \mathrm{inHg}$ & $24.8 \mathrm{inHg}$ & $24.8 \mathrm{inHg}$ \\
\hline Humidity (\%) & $17.6 \% \mathrm{RH}$ & $17.6 \% \mathrm{RH}$ & $17.6 \% \mathrm{RH}$ & $17.6 \% \mathrm{RH}$ & $17.6 \% \mathrm{RH}$ \\
\hline
\end{tabular}

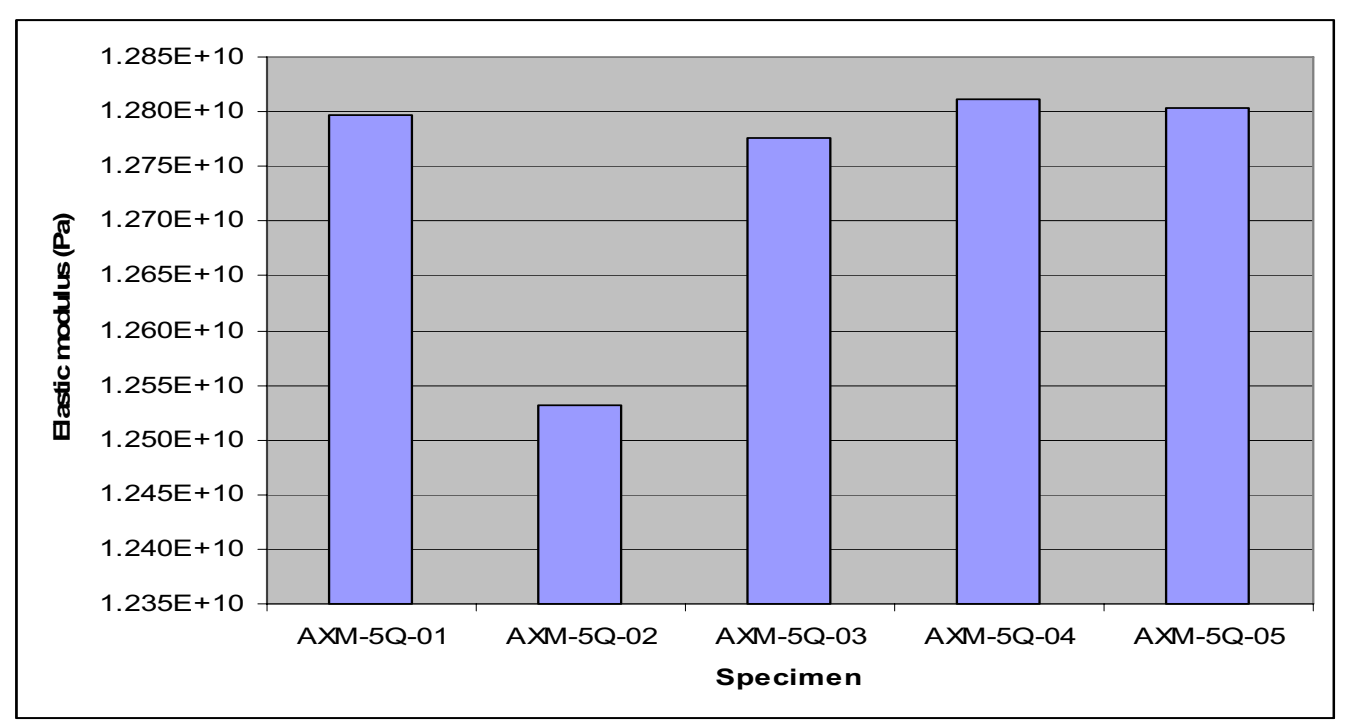




\section{Thermal Diffusivity}

\#\#Thermal_diffusivity_Avg

\begin{tabular}{|c|c|c|}
\hline \#General_information & & \\
\hline \#Database & axm-5q \#6 \#7 \#8.mdk & \\
\hline \#Instrument & \#LFA_457 & \\
\hline \#Identity & AXM-5̄ \#6 \#7 \#8 & \\
\hline \#Date/Time & $2 / 5 / 2009$ & 9 11:21 \\
\hline \#Material & AXM-5Q & \\
\hline \#Ref_temperature $/{ }^{\circ} \mathrm{C}$ & & 23 \\
\hline \#Ref_density /(g/cm^3) & & 1.738 \\
\hline \#Sample & AMX-5Q \#6,7,8,9,10 & \\
\hline \#Туре & \#Single_layer & \\
\hline \#Coating & none & \\
\hline \#Thickness_RT/mm & & 6.4017 \\
\hline \#Diameter/mm & & 12.713 \\
\hline \#Sensor & $\operatorname{lnSb}$ & \\
\hline \#Beam_enlargement/mm & & 12.7 \\
\hline \#Laser_filter/mm & & 100 \\
\hline \#Atmosphere & $\mathrm{Ar}$ & \\
\hline \#Gas_flow/(ml/min) & & 100 \\
\hline \#Laboratory & INL & \\
\hline \#Operator & dch & \\
\hline \#Customer & NGNP & \\
\hline \#Remark_mment & AXM-5Q samples \#6 & \\
\hline \#Cp_table & \#undefined & \\
\hline \#Expansion_table & \#undefined & \\
\hline $\begin{array}{l}\text { \#Temp_recalib_file } \\
\text { \#Purge gas }\end{array}$ & Tcalzero.tcx & \\
\hline \#CalcCode & $C+p / 1 / x-x-0$ & \\
\hline
\end{tabular}

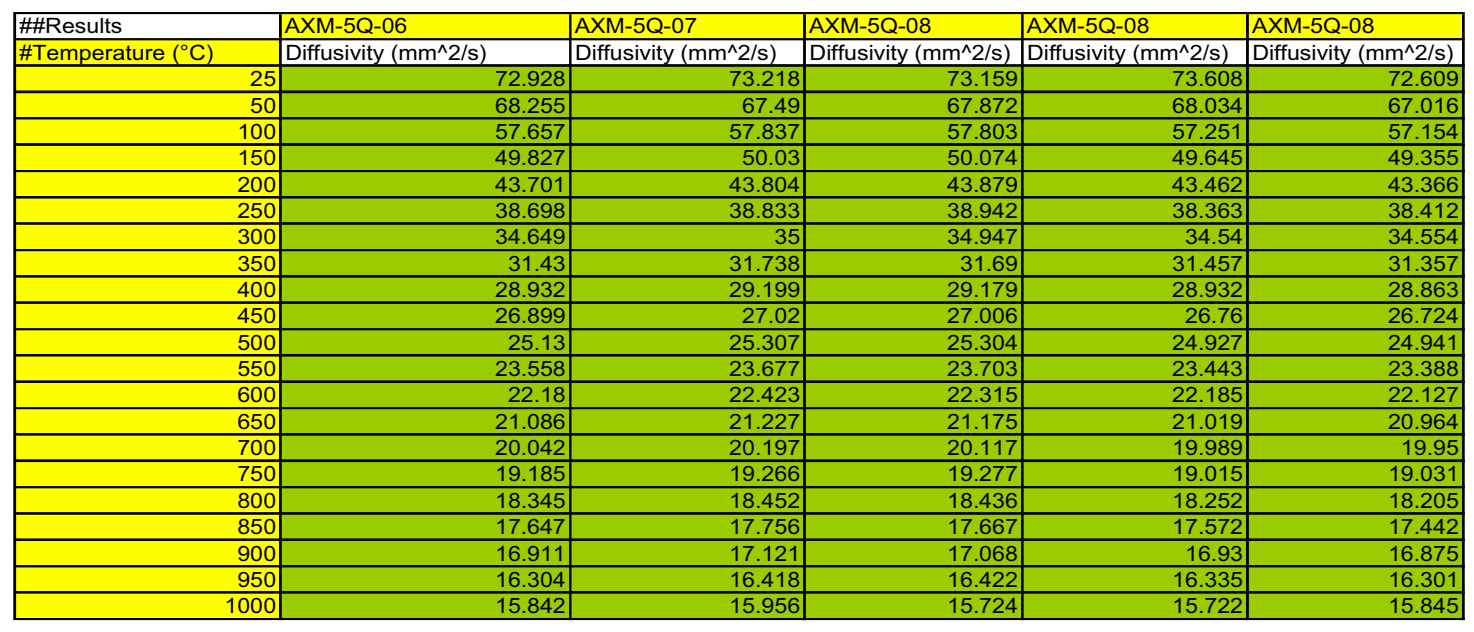

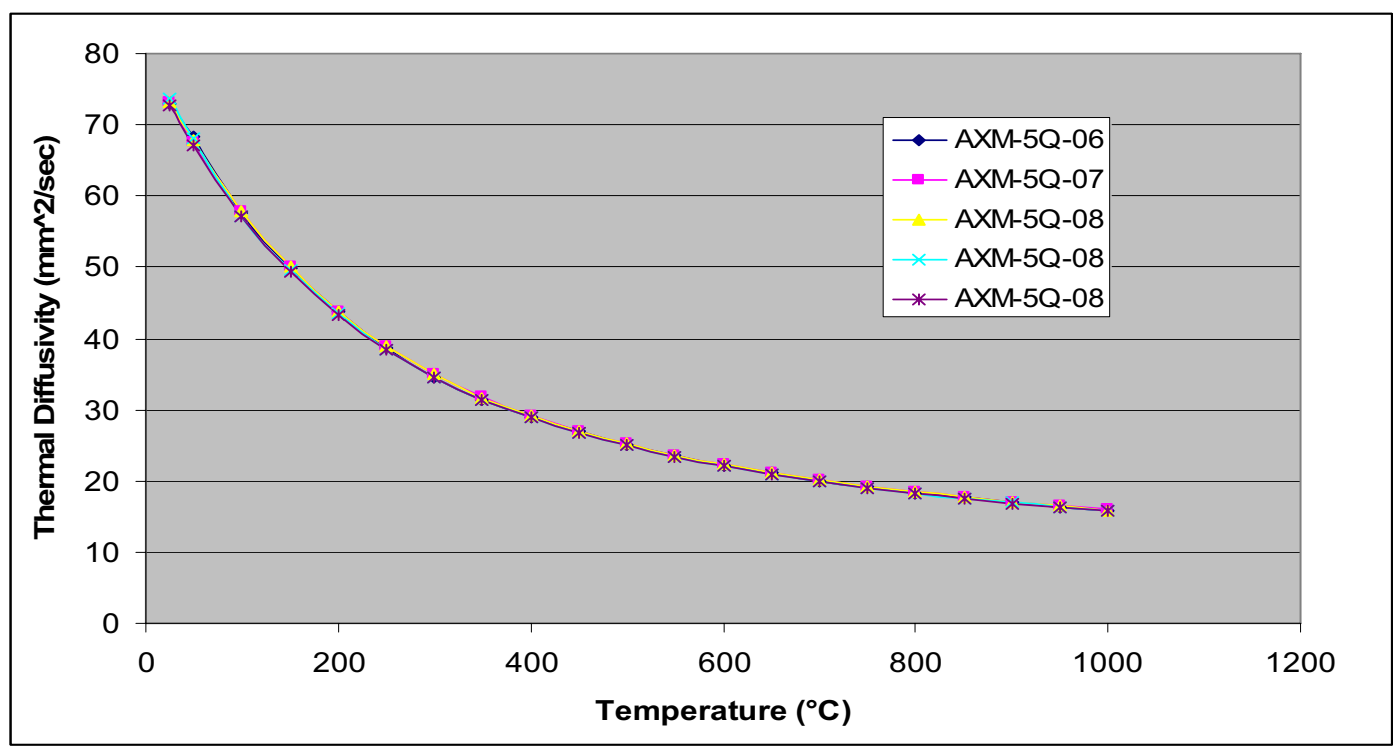




\section{Coefficient of Thermal Expansion}

\#FILE:

\#FORMAT:

\#IDENTITY:

\#DECIMAL:

\#SEPARATOR:

\#MTYPE:

\#INSTRUMENT:

\#PROJECT:

\#DATE/TIME:

\#CORR. FILE:

\#LABORATORY:

\#OPERATOR:

\#REMARK

\#SAMPLE:

\#SAMPLE LENGTH /m

\#MATERIAL:

\#MEASMODE:

\#PURGE GAS 1:

\#FLOW RATE $1 /(\mathrm{ml} / \mathrm{mi}$

\#CORR. CODE:

\#RANGE:

\#SEGMENT:
AXM-5Q-03.dle AXM-5Q-04.dle AXM-5Q-05.dle AXM-5Q-02 run2.dle

NETZSCH5 NETZSCH5 NETZSCH5 NETZSCH5

$\begin{array}{lll}\text { AXM-5Q-03 AXM-5Q-04 AXM-5Q-05 AXM-5Q-02 run2 } & \text { A }\end{array}$

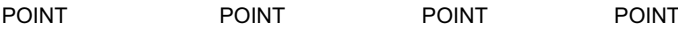

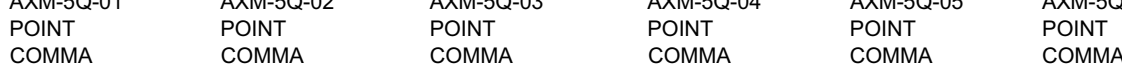

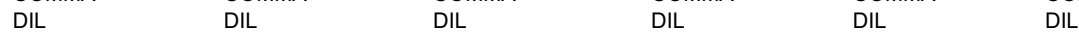

NETZSCH DIL 402 C NETZSCH DIL 402 C NETZSCH DIL 402 C NETZSCH DIL 402 (NETZSCH DIL 402 NETZSCH DIL 402 C $\begin{array}{llllll}\text { sapphire } & \text { AGC2 } & \text { AGC2 } & \text { AGC2 } & \text { AGC2 } & \text { AGC2 }\end{array}$

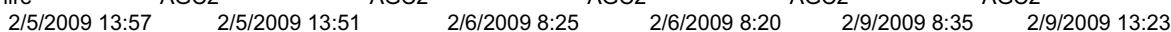

Ne sapp $100 \_083$ de Ne sapp $101 \_83$ de Ne sapp $100 \_083$ deç Ne sapp 101083 diNe sapp $100 \_083$ ( Ne sapp 101 08 3 deg run2.cle IRC INL $\quad$ IRC INL IRC IN

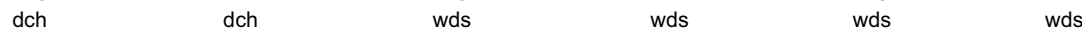

$\begin{array}{lllll}\text { AXM-5Q-01 AXM-5Q-02 AXM-5Q-03 AXM-5Q-04 AXM-5Q-05 } \quad \text { AXM-5Q-02 run2 } & \text { AX }\end{array}$

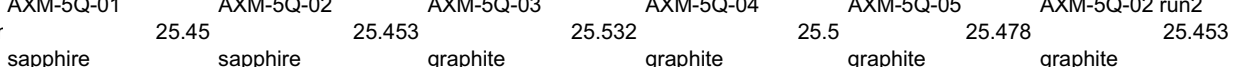

Standard Expansion Standard Expansion Standard Expansion Standard Expansion Standard Expansior Standard Expansion

argon

$\mathrm{Ar} \quad$ argon

$\mathrm{Ar} \quad$ argon

0

60

$\mathrm{Ar}$

0

$0 \quad 0$

30.0/3.0(K/min)/1040.30.0/3.0(K/min)/1040.30.0/3.0(K/min)/1040. $30.0 / 3.0(\mathrm{~K} / \mathrm{min}) / 104$ (30.0/3.0(K/min)/104 30.0/3.0(K/min)/1040.0

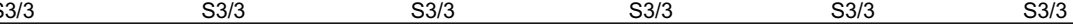

\begin{tabular}{|c|c|c|c|c|c|c|}
\hline & AXM-5Q-01 & AXM-5Q-02 & AXM-5Q-03 & AXM-5Q-04 & AXM-5Q-05 & AXM-5Q-02 run2 \\
\hline \#\#Temp. /øC & T. Alpha/(1/K) & T. Alpha/(1/K) & T. Alpha/(1/K) & T. Alpha/(1/K) & T. Alpha/(1/K) & T. Alpha/(1/K) \\
\hline 100 & $7.25 \mathrm{E}-06$ & $6.98 \mathrm{E}-06$ & $7.21 \mathrm{E}-06$ & $7.15 \mathrm{E}-06$ & $7.22 \mathrm{E}-06$ & 7.04E-06 \\
\hline 200 & $7.23 \mathrm{E}-06$ & $7.08 \mathrm{E}-06$ & $7.21 \mathrm{E}-06$ & $7.22 \mathrm{E}-06$ & $7.23 \mathrm{E}-06$ & $7.11 \mathrm{E}-06$ \\
\hline 300 & $7.37 \mathrm{E}-06$ & $7.29 \mathrm{E}-06$ & $7.35 \mathrm{E}-06$ & $7.40 \mathrm{E}-06$ & $7.36 \mathrm{E}-06$ & $7.30 \mathrm{E}-06$ \\
\hline 400 & $7.58 \mathrm{E}-06$ & $7.50 \mathrm{E}-06$ & $7.52 \mathrm{E}-06$ & $7.58 \mathrm{E}-06$ & $7.52 \mathrm{E}-06$ & $7.48 \mathrm{E}-06$ \\
\hline 500 & $7.68 \mathrm{E}-06$ & $7.65 \mathrm{E}-06$ & $7.64 \mathrm{E}-06$ & $7.72 \mathrm{E}-06$ & $7.63 \mathrm{E}-06$ & $7.63 \mathrm{E}-06$ \\
\hline 600 & $7.78 \mathrm{E}-06$ & $7.76 \mathrm{E}-06$ & $7.74 \mathrm{E}-06$ & $7.82 \mathrm{E}-06$ & $7.73 \mathrm{E}-06$ & $7.74 \mathrm{E}-06$ \\
\hline 700 & $7.86 \mathrm{E}-06$ & $7.90 \mathrm{E}-06$ & $7.82 \mathrm{E}-06$ & $7.93 \mathrm{E}-06$ & $7.82 \mathrm{E}-06$ & $7.86 \mathrm{E}-06$ \\
\hline 800 & $7.94 \mathrm{E}-06$ & $8.01 \mathrm{E}-06$ & $7.88 \mathrm{E}-06$ & $8.04 \mathrm{E}-06$ & $7.89 \mathrm{E}-06$ & $7.98 \mathrm{E}-06$ \\
\hline 900 & $8.02 \mathrm{E}-06$ & $8.11 \mathrm{E}-06$ & $7.95 \mathrm{E}-06$ & $8.13 \mathrm{E}-06$ & $7.97 \mathrm{E}-06$ & $8.07 \mathrm{E}-06$ \\
\hline 1000 & $8.10 \mathrm{E}-06$ & 8.19E-06 & $8.04 \mathrm{E}-06$ & $8.22 \mathrm{E}-06$ & $8.06 \mathrm{E}-06$ & $8.16 \mathrm{E}-06$ \\
\hline
\end{tabular}

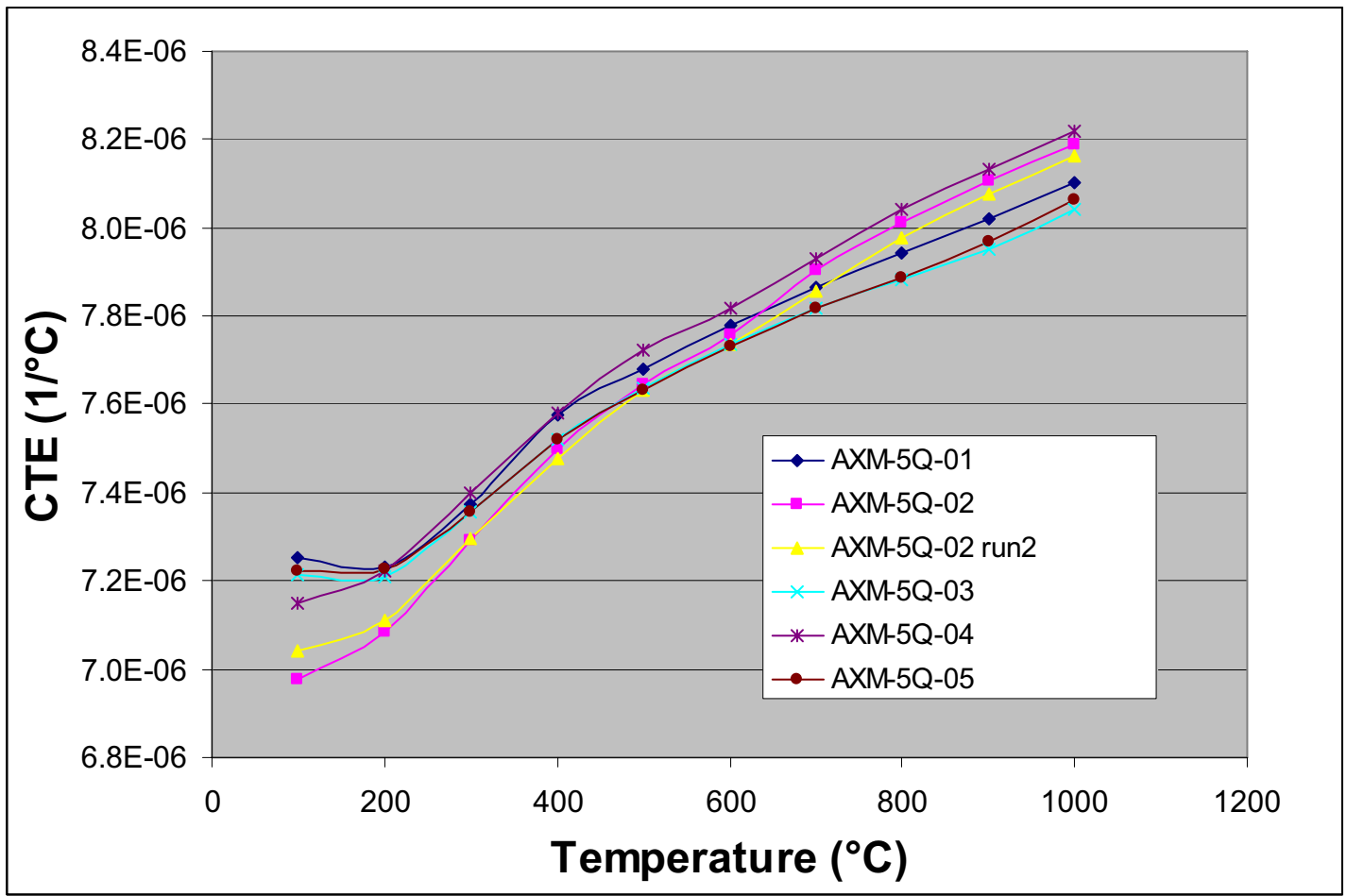

